\title{
LA CRISIS DE LA TRANSICIÓN DEMOGRÁFICA EN EL ÁFRICA SUBSAHARIANA: POBREZA Y POBLACIÓN EN EL MUNDO ACTUAL
}

\author{
Juan-Francisco Martín Ruiz \\ Departamento de Geografía \\ Universidad de La Laguna
}

\section{RESUMEN}

África es el continente con mayor retraso en el desarrollo demográfico en su conjunto, y sobre todo la situada al Sur del Sahara es la que ha experimentado en la última década una fuerte ralentización, surgiendo una nueva brecha, que parece aumentar en los últimos años. Incide directamente la pobreza, de modo que hay una interrelación entre población y desarrollo socioeconómico y humano. Interactúan como factores limitativos la alta fecundidad, el gran crecimiento demográfico, la escasa escolarización y elevadísimo analfabetismo, sobre todo de la mujer, así como la manifestación de nuevas epidemias: VIH/SIDA, tuberculosis, y el agravamiento de antiguas endemias, la malaria y las derivadas de las grandes hambrunas y crisis bélicas. Exige un gasto añadido (potencial) en salud y se produce un descenso de la productividad, y todo ello conlleva que se detenga el desarrollo humano, el progreso demográfico y social, e incluso la incipiente transición epidemiológica y la transición demográfica misma. Así, a la primera brecha, la del continente africano en su conjunto con respecto al Primer Mundo, se añade una nueva, entre África al Sur del Sahara y la del Norte, empobrecida la primera, en muchos de cuyos países se ha paralizado en incluso retrocedido la transición sanitaria y demográfica, y en vías de desarrollo económico y humano la segunda, con una transición demográfica ya en una fase relativamente avanzada.

Palabras clave: Pobreza, deuda externa, desarrollo humano, fecundidad natural, transición demográfica

\section{RÉSUMÉ}

L'Afrique est le continent avec le plus fort retard dans le développement démographique dans l'ensemble et, surtout la partie située au sud du Sahara, est celle qui a expérimentée dans la dernière décennie un fort ralentissement, en naissant une nouvelle brèche, qui paraît avoir augmenté dans les dernières années. La pauvreté a une incidence directe, de façon qu'il y a une interrelation entre la population et le développement socioéconomique et humain. La fécondité élevée, l’important développement démographique, la faible scolarisation et le si élevé analphabétisme, surtout de la femme, interagissent 
comme des facteurs limitatifs, ainsi que la manifestation de nouvelles épidémies : HIV/ Sida, tuberculose, et l'aggravation des antiques endémies, la malaria, et les dérivées des grandes famines et crises de guerre. Cela exige une dépense extra (potentielle) à santé et produit une baisse de la productivité, et tout cela implique que le développement humain, le progrès démographique et social et, même la naissante transition épidémiologique et la transition démographique elle-même s'arrêtent. Ainsi, à la première brèche, celle du continent africain dans l'ensemble au sujet du Premier Monde, on en ajoute une nouvelle, entre l'Afrique du sud du Sahara et celle du nord, appauvrie la première, dans laquelle beaucoup de pays la transition sanitaire et démographique se sont paralysées et, même reculées, et en voies de développement économique et humaine la seconde, avec une transition démographique dans une phase déjà relativement avancée.

Mots clés: pauvreté, dette externe, développement humain, fécondité naturelle, transition démographique.

\section{Introducción}

África Subsahariana es hoy la unidad regional más pobre del mundo, manifestándose en todas las variables macroeconómicas, sociales y demográficas (baja renta por habitante, escaso desarrollo humano, alta fecundidad, mortalidad infantil aún muy elevada, baja vida media). Pretendo analizar y dilucidar las pautas geodemográficas subsaharianas, en sus grandes tendencias, y en qué fase de la transición demográfica se halla el subcontinente, haciendo hincapié en la interrelación dialéctica pobreza-población.

Las hipótesis de partida son las siguientes:

1. En el subcontinente subsahariano la ruptura del orden bipolar, con la manifestación del capitalismo en su fase de globalización, ha detenido el desarrollo socioeconómico y humano, situándolo fuera de ese proceso, esto es, al margen del centro económico y geopolítico mundial, lo que se ha traducido también en el orden geodemográfico. Así, una gran parte de sus países se aleja progresivamente de la convergencia, acentuándose las desigualdades, y en particular la brecha con el Primer Mundo, aunque también se manifiesta, en todos los órdenes, una brecha con África Septentrional.

2. La pobreza y la detención de los caminos a la convergencia paralizan la evolución del desarrollo y transición demográficas de África al Sur del Sahara, incidiendo negativamente en el control de la fecundidad, de la mortalidad a todas las edades, pero sobremanera en la infantil e infancia, al tiempo que han dado lugar primero a la aparición de nuevas epidemias, como la del VIH/SIDA; y segundo, al agravamiento de antiguas morbilidades, en muchos casos cuasi endémicas de muchas regiones, como la malaria y enfermedades de la infancia, porque al caer la tasa de ahorro interno, el gasto público en salud no aumenta al ritmo necesario, lo que se traduce también en el descenso de la vida media, que en muchos países ha descendido de los 60-70 años a los 40-50 años de edad. La consecuencia es que la transición epidemiológica se ha detenido, comprometiendo la transición demográfica, a lo que contribuye la aparición de hambrunas y el surgimiento de conflictos bélicos de carácter civil en muchas ocasiones. Inciden en el aumento de la mortalidad, pero también en la desarticulación de las estructuras estatales, de modo que la inestabilidad política, derivada en buena medida de la situación colonial del pasado y neocolonial del presente, se transforma en un obstáculo al crecimiento y al desarrollo económico y sociodemográfico. 
Para el análisis y verificación de las hipótesis se han elegido, de entre los países más pobres, aquéllos para los que se dispone de información suministrada por sus propios organismos de estadística, relativas a estadísticas económicas y sociodemográficas que permitan la formación de alguna serie cronológica, aunque sea corta e incompleta, a los que se han añadido dos países de África Austral, Sudáfrica y Botswana, con cierto desarrollo económico, pero con problemas de retroceso en su transición epidemiológica. Son en total 12 países: Mauritania, Níger, Burkina Faso, Sierra Leona, Costa de Marfil, Guinea Ecuatorial, Congo, República Centroafricana, Mozambique, Malawi, Botswana y Sudáfrica. A ellos se ha añadido Chad, Malí, Guinea, Guinea Bissau y Senegal, para los que se disponía de otro tipo de información, procedente de organismos internacionales ${ }^{1}$. Se ha procurado contrastar siempre la información suministrada por los organismos de estadísticas de los países elegidos con la procedente de los organismos internacionales, tanto de Naciones Unidas, como del Banco Mundial, Fondo Monetario Internacional, UNICEF, Organización Mundial de la Salud, entre otros. El resultado es satisfactorio, porque aun cuando en líneas generales hay que considerar que los datos son aproximativos, al hallarse debidamente contrastados y depurados, evidencian las grandes líneas de tendencia.

\section{El bajísimo nivel de desarrollo socioeconómico y humano}

Desde los años 90 de la centuria pasada el subcontinente subsahariano se aleja de la denominada convergencia económica, situado ya fuera del centro geoeconómico mundial, en una exclusión casi absoluta; se acentúan las desigualdades, y en particular la brecha con el Primer Mundo, aunque también con el Norte de África. La globalización liberal determina que el capitalismo incluya unas áreas y excluya a otras, creando al mismo tiempo riqueza en unas regiones y pobreza en otras, como señala Sami Naïr $(2003)^{2}$. A pesar de que en los últimos años la renta por habitante ha crecido algo, hoy se sitúa en un valor bajísimo, de solo 2.580 dólares por habitante ${ }^{3}$ en promedio, correspondiéndose lógicamente con un Índice de Desarrollo Humano (IDH) ${ }^{4}$ igualmente muy deficiente, de solo 0,46 (Cuadro 2).

La brecha en la distribución de la renta por habitante se manifiesta con claridad, porque para 2003, África Septentrional alcanza el valor de 4.281 (PPA \$), casi duplicando la renta del área al sur de Sahara, lo que significa que la primera evoluciona lentamente hacia la convergencia económica ${ }^{5}$, en tanto que la segunda se aleja. Esta renta, medida en PIB real por habitante, es bastante más baja, de sólo 1.245 para la primera, y de 916 para

1 Se ha prescindido de algunos países muy pobres de África oriental, como Etiopía, Burundi, Tanzania, por la carencia de información estadística fidedigna.

2 Este autor afirma que «ningún continente ha sufrido como África las devastadoras consecuencias de la globalización liberal» y que «hoy, solo hay dos mundos: el que está dentro y el que está fuera de la globalización» (Bibliografía).

3 Medida en términos de PPA\$ de EE UU, porque en valores reales es muy inferior, en torno a 916 (Cuadro 1).

4 El IDH es un indicador sinóptico y compuesto desarrollado por el PNUD que se aplica desde 1990, y que tiene en cuenta tres factores o componentes: la renta por habitante, que mide el grado de bienestar económico, la vida media, como indicador de las condiciones de salud de la población y el nivel de instrucción, a partir del índice de la tasa de alfabetización de adultos y la tasa bruta combinada de escolarización, que mide el grado de desarrollo educativo.

Véase en línea: http://www.desarrollohumano.org.sv/

5 Aunque aún se halla alejada de los 10.000 \$ que algunos autores señalan como umbral que separa las regiones desarrolladas de las subdesarrolladas (Cándido Muñoz, 1994). En este sentido, la media mundial se halla por debajo del umbral, 8.229, lo que da una medida del peso de los países no desarrollados y de las grandes desigualdades entre los países muy ricos y los más pobres, casi todos africanos. 
Cuadro 1

EVOLUCIÓN DEL PIB POR HABITANTE

\begin{tabular}{|c|c|c|c|c|}
\hline & 1983 & 1991 & $\begin{array}{c}\text { PIB h } \\
\text { (PPA)2003 }\end{array}$ & PIB h real 2003 \\
\hline Mauritania & 440 & 962 & 1.849 & 384 \\
\hline Burkina Faso & 180 & 666 & 1.163 & 345 \\
\hline Chad & - & 447 & 1.210 & 304 \\
\hline Malí & 150 & 480 & 994 & 371 \\
\hline Níger & 240 & 542 & 835 & 232 \\
\hline Guinea & 300 & 430 & 2.097 & 459 \\
\hline Guinea Bissau & 180 & 180 & 782 & 160 \\
\hline Senegal & - & 1.680 & 1.618 & 634 \\
\hline Sierra Leona & - & 1.020 & 562 & 149 \\
\hline Costa de Marfil & 720 & 1.510 & 1.476 & 816 \\
\hline Ghana & 320 & 930 & 2.250 & 369 \\
\hline Congo & 1.230 & 2.800 & 1.059 & 949 \\
\hline Guinea Ecuatorial & - & 700 & 19.209 & 5.900 \\
\hline $\begin{array}{l}\text { República } \\
\text { Centroafricana }\end{array}$ & 280 & 641 & 1.156 & 309 \\
\hline Malawi & 210 & 800 & 616 & 156 \\
\hline Mozambique & - & 921 & 1.117 & 230 \\
\hline Botswana & 920 & 4.690 & 9.382 & 4.372 \\
\hline $\begin{array}{l}\text { República } \\
\text { Sudafricana }\end{array}$ & - & 3.885 & 10.045 & 3.489 \\
\hline $\begin{array}{l}\text { África } \\
\text { Septentrional }\end{array}$ & 1.736 & 3.077 & 4.281 & 1.245 \\
\hline $\begin{array}{l}\text { África } \\
\text { Subsahariana }\end{array}$ & - & 1.351 & 2.580 & 916 \\
\hline África & & 1.665 & 2.889 & 976 \\
\hline
\end{tabular}

Fuente: Banco Mundial, Atlas del Banco Mundial e Informe sobre el Desarrollo Mundial (varios años); Informe sobre Desarrollo Humano, PNUD; UNICEF. Elaboración propia.

la segunda, valores que pueden acercarnos algo más a la dura realidad de la dimensión de la pobreza de África en su conjunto (976 \$), con un IDH de sólo 0,575, aunque los países del Norte del continente superan el valor de 0,7, situados ya en el camino del desarrollo socioeconómico. Por debajo de la media del subcontinente, 2.580 de renta en PPA \$ y 916 dólares corrientes, se halla la mayoría de los países en estudio, que ofrecen también un 
bajo índice de crecimiento del PIB, en muchos casos con valores negativos, y un desarrollo humano escaso ${ }^{6}$.

Los países más pobres son, en general, los del Sahel, incluida Mauritania, con rentas muy bajas, en torno a los 1.000 \$ PPA y 300 corrientes, IDH inferior a 0,3 y tasas de crecimiento del PIB muy bajas, e incluso negativas, como es el caso de Níger y Malí, que ofrecen a su vez una proporción de población, próxima a $2 / 3$ del total, que vive en la pobreza extrema, con menos de un dólar al día. A ellos se debe añadir algunos países de África Occidental, tales como Senegal, Guinea, Guinea Bissau, Costa de Marfil y sobre todo Sierra Leona, país que por la cruenta guerra civil, que comenzó en 1991 y finalizó una década después, atraviesa por una crisis que se manifiesta en todas la variables macroeconómicas y sociales: en 2003 sólo 562 \$ PPA, 0,273 de Desarrollo Humano, 57\% de población que vive con menos de un dólar al día, tasa anual de crecimiento económico negativa en el período 1990-2004, de -2,5, partiendo ya de un valor negativo en 1970-19907.

En África Central la situación de pobreza es similar, pues en la República Centroafricana y $\mathrm{Congo}^{8}$ los indicadores en general no mejoran gran cosa, a excepción de Guinea Ecuatorial, que por la exportación de crudo, ha visto cómo su crecimiento económico se incrementa bastante en la última década; ha tirado, probablemente de una forma algo ficticia, del desarrollo humano, porque las disparidades sociales son en ese país muy elevadas, con fortísimas deficiencias. Esta situación la corrobora el hecho de que el gasto público en \% del PIB en 2004 sea en educación sólo de 0,6 y en salud de 2,3, valores muy inferiores al promedio del subcontinente? .

En África oriental la precariedad no decrece, como indican los valores macroeconómicos de los países de la región, entre los que estudiamos Malawi y Mozambique, de modo que en el primero la pobreza es de tal magnitud, que la renta media asciende a sólo $616 \$$ PPA, y 156 corrientes, un Desarrollo Humano de 0,39, una tasa de crecimiento del PNB desde 1990 de apenas $1 \%$ anual y más del $40 \%$ de la población que vive con menos de un dólar al día; en el segundo, en Mozambique, la situación parece que ha mejorado algo en los últimos años ${ }^{10}$, aunque la renta apenas supera los 1.000 dólares, 230 corrientes, el valor de Desarrollo Humano es de 0,35, registrándose, no obstante, un incremento importante del PNB anual por habitante; aún así, cerca del $40 \%$ de la población vive con menos de un dólar al día.

Por último, en África Austral, Botswana y Sudáfrica, con rentas en \$ PPA de 9.382 y 10.045 , IDH de 0,59 y 0,67 , presentan un evidente grado de desarrollo, con un gran sector

6 Presentan también los porcentajes más elevados de población que vive con menos de un dólar al día. Forman todos los países en estudio, a excepción de Guinea Ecuatorial (por el desarrollo petrolero reciente), y Sudáfrica, que ha actuado en cierto modo como locomotora (industrial) de los países de África Austral, y también de Botswana.

7 El resto de los países de África Occidental no presenta en general una situación mucho más favorable, pues los indicadores aun mejorando algo, los sitúa entre los países más pobres del mundo. Únicamente Guinea parece despuntar algo, con una renta ya algo superior a los 2.000 \$ PPA y una tasa de crecimiento de su PNB en torno a $1,5 \%$ en el periodo mencionado (Vid cuadro 3), en realidad insuficiente para emprender el camino a la convergencia.

8 Quizás la realidad de la República Democrática del Congo, e incluso de Gabón, puede resultar más crítica.

9 Vid Informe sobre Desarrollo Humano, PNUD, de 2005.

10 La guerra civil en Mozambique, tras 16 años, concluye en 1992 con los acuerdos de paz entre el gobierno y los grupos guerrilleros, dejando a la población sumida en una gran crisis pues la guerra destruyó mucha de la infraestructura del país, ocasionó 1 millón de muertes y desplazó a unos 6 millones de personas, según estimaciones del Comité de Estados Unidos para Refugiados. Vid U.S. Committee for Refugees, «Country Report: Mozambique (1997)».

(En línea: http:// www.refugees.org/world/countryrpt/africa/ 1997/mozambique.htm. 


\section{Cuadro 2}

EVOLUCIÓN DE LOS ÍNDICES DE DESARROLLO HUMANO

\begin{tabular}{|l|l|l|l|l|}
\hline & $\mathbf{1 9 7 5}$ & $\mathbf{1 9 8 5}$ & $\mathbf{1 9 9 2}$ & $\mathbf{2 0 0 3}$ \\
\hline Mauritania & 0,340 & 0,384 & 0,254 & 0,465 \\
\hline Burkina Faso & 0,253 & 0,297 & 0,203 & 0,302 \\
\hline Chad & 0,269 & 0,311 & 0,212 & 0,379 \\
\hline Malí & 0,230 & 0,256 & 0,214 & 0,326 \\
\hline Níger & 0,236 & 0,242 & 0,209 & 0,292 \\
\hline Guinea & - & - & 0,450 & 0,425 \\
\hline Guinea Bissau & 0,255 & 0,283 & 0,224 & 0,350 \\
\hline Congo & 0,452 & 0,540 & 0,461 & 0,494 \\
\hline Guinea Ecuatorial & - & - & 0,276 & 0,655 \\
\hline Senegal & 0,311 & 0,375 & 0,332 & 0,437 \\
\hline Sierra Leona & - & - & 0,209 & 0,273 \\
\hline Costa de Marfil & 0,409 & 0,448 & 0,370 & 0,399 \\
\hline República Centroafricana & 0,343 & 0,386 & 0,249 & 0,361 \\
\hline Malawi & 0,320 & 0,362 & 0,260 & 0,388 \\
\hline Mozambique & - & 0,287 & 0,252 & 0,354 \\
\hline Botswana & 0,503 & 0,638 & 0,670 & 0,589 \\
\hline República Sudafricana & 0,650 & 0,674 & 0,650 & 0,666 \\
\hline África Subsahariana & $\mathbf{0 , 3 7 6}$ & $\mathbf{0 , 4 1 8}$ & $\mathbf{0 , 3 2 2}$ & $\mathbf{0 , 4 5 5}$ \\
\hline África septentrional & $\mathbf{0 , 4 4 7}$ & $\mathbf{0 , 5 2 4}$ & $\mathbf{0 , 5 5 0}$ & $\mathbf{0 , 7 0 9}$ \\
\hline África & $\mathbf{0 , 5 3 6}$ & $\mathbf{0 , 6 0 8}$ & $\mathbf{0 , 5 4 7}$ & $\mathbf{0 , 5 7 5}$ \\
\hline
\end{tabular}

Fuente: Informe sobre Desarrollo Humano, PNUD; UNICEF. Elaboración propia

minero-industrial exportador(diamantes y oro respectivamente), sobre todo en el contexto subsahariano, pero con grandes paradojas por cuanto que la aparición como epidemia del VIH/SIDA y la tuberculosis, asociada a ella casi siempre, más las grandes diferencias entre la minoría blanca, que detenta el poder económico, y la mayoría negra, con el poder político $^{11}$, ha dislocado el desarrollo económico y sobre todo social, retrasando de una manera clara la convergencia. Se manifiesta con claridad en las variables macroeconómicas, pero sobre todo en las sociales y geodemográficas, como veremos.

En resumen, hay una pobreza casi general a toda el África Subsahariana, con ciertas diferencias regionales y de un país a otro, pero con la excepción de África Austral, que a pesar de las paradojas de su desarrollo económico, con Sudáfrica de locomotora y gran potencial regional, se ha convertido en la única región dinámica del subcontinente.

11 Las desigualdades sociales entre la mayoría negra y la minoría blanca son muy importantes aún, no sólo en la distribución de la renta, sino también en los servicios sociales, educativos y sanitarios. 


\section{El gran crecimiento demográfico y la fortísima expansión de la población de las áreas urbanas}

Datar la fecha en que la población del subcontinente inicia su despegue en el crecimiento demográfico, resulta difícil ${ }^{12}$, porque significa establecer la cronología misma del comienzo de la transición demográfica, en particular del inicio del control de la mortalidad. Sea como fuere, parece evidente que entre mediados de los 70 y los 80 se produce en una gran parte de los países una cierta aceleración del saldo natural, por descenso de la mortalidad general, que se traduce en un crecimiento demográfico sustantivo, pudiéndose alcanzar una tasa media anual acumulada en torno a 3\%, variable en cualquier caso de un país a otro.

Cuadro 3

EVOLUCIÓN DE LAS TASAS MEDIAS ANUALES DE CRECIMIENTO ACUMULADO DE LA POBLACIÓN

\begin{tabular}{|l|c|c|c|}
\hline & $\mathbf{1 9 7 5 - 1 9 8 3}$ & $\mathbf{1 9 8 3 - 1 9 9 1}$ & $\mathbf{1 9 9 1 - 2 0 0 3}$ \\
\hline Mauritania & 2,0 & 3,1 & 2,8 \\
\hline Burkina Faso & 1,5 & 4,8 & 2,6 \\
\hline Chad & 1,5 & 3,0 & 3,0 \\
\hline Malí & 2,0 & 2,6 & 3,1 \\
\hline Níger & 1,7 & 3,9 & 3,2 \\
\hline Guinea & 4,2 & 0,1 & 2,9 \\
\hline Guinea Bissau & 2,7 & 2,1 & 3,1 \\
\hline Congo & 2,1 & 4,2 & 3,6 \\
\hline Guinea Ecuatorial & 7,6 & 2,4 & 1,2 \\
\hline Senegal & 2,0 & 3,0 & 2,2 \\
\hline Sierra Leona & 1,5 & 3,8 & 1,2 \\
\hline Costa de Marfil & 4,4 & 4,1 & 2,3 \\
\hline República Centroafricana & 2,0 & 3,4 & 1,7 \\
\hline Malawi & 3,2 & 4,0 & 2,5 \\
\hline Mozambique & 2,9 & 2,8 & 1,2 \\
\hline Botswana & 1,3 & 3,7 & 2,5 \\
\hline República Sudafricana & 2,4 & 2,3 & 1,6 \\
\hline África Subsahariana & $\mathbf{3 , 1}$ & $\mathbf{3 , 4}$ & $\mathbf{2 , 2}$ \\
\hline África & $\mathbf{2 , 8}$ & $\mathbf{3 , 3}$ & $\mathbf{2 , 4}$ \\
\hline
\end{tabular}

Fuente: Informe sobre Desarrollo Humano, PNUD; UNICEF; United Nations: World Population Prospects. Elaboración propia.

12 P-J. Thumerelle (1996) señala que la población de África Subsahariana comenzó a crecer en el período de entreguerras, e incluso a principios de siglo XX, evolucionando de 100 millones de habitantes en 1900 a 140 150 millones hacia 1940-50(Vid Bibliografía). 


\section{Cuadro 4}

EVOLUCIÓN DE LAS TASAS BRUTAS DE NATALIDAD Y MORTALIDAD,
Y DEL SALDO VEGETATIVO $\left(\%_{,}\right)$

\begin{tabular}{|c|c|c|c|c|c|c|c|c|c|}
\hline & \multicolumn{3}{|c|}{$\begin{array}{c}\text { Tasa bruta de } \\
\text { natalidad }\end{array}$} & \multicolumn{3}{|c|}{$\begin{array}{l}\text { Tasa bruta de } \\
\text { mortalidad }\end{array}$} & \multicolumn{3}{|c|}{ Saldo vegetativo } \\
\hline & 1970 & 1990 & 2004 & 1970 & 1990 & 2004 & 1970 & 1990 & 2004 \\
\hline Botswana & 48,0 & 34,0 & 26,0 & 13,0 & 6,0 & 27,0 & 35,0 & 28,0 & $-1,0$ \\
\hline Burkina Faso & 50,0 & 50,0 & 47,0 & 23,0 & 18,0 & 17,0 & 27,0 & 32,0 & 30,0 \\
\hline $\begin{array}{l}\text { República } \\
\text { Centroafricana }\end{array}$ & 43,0 & 42,0 & 37,0 & 22,0 & 17,0 & 22,0 & 21,0 & 25,0 & 15,0 \\
\hline Chad & 48,0 & 48,0 & 48,0 & 25,0 & 19,0 & 20,0 & 23,0 & 29,0 & 28,0 \\
\hline Congo & 44,0 & 44,0 & 44,0 & 14,0 & 12,0 & 13,0 & 30,0 & 32,0 & 31,0 \\
\hline Costa de Marfil & 51,0 & 45,0 & 37,0 & 18,0 & 14,0 & 17,0 & 33,0 & 31,0 & 20,0 \\
\hline Guinea Ecuatorial & 42,0 & 44,0 & 43,0 & 25,0 & 20,0 & 20,0 & 17,0 & 24,0 & 23,0 \\
\hline Ghana & 46,0 & 40,0 & 31,0 & 17,0 & 12,0 & 11,0 & 29,0 & 28,0 & 20,0 \\
\hline Guinea & 50,0 & 45,0 & 42,0 & 27,0 & 18,0 & 14,0 & 23,0 & 27,0 & 28,0 \\
\hline Guinea-Bissau & 49,0 & 50,0 & 50,0 & 29,0 & 23,0 & 20,0 & 20,0 & 27,0 & 30,0 \\
\hline Malawi & 56,0 & 51,0 & 44,0 & 24,0 & 19,0 & 21,0 & 32,0 & 32,0 & 23,0 \\
\hline Malí & 55,0 & 50,0 & 49,0 & 28,0 & 20,0 & 17,0 & 27,0 & 30,0 & 32,0 \\
\hline Mauritania & 46,0 & 43,0 & 41,0 & 21,0 & 17,0 & 14,0 & 25,0 & 26,0 & 27,0 \\
\hline Mozambique & 48,0 & 44,0 & 40,0 & 24,0 & 21,0 & 20,0 & 24,0 & 23,0 & 20,0 \\
\hline Níger & 58,0 & 57,0 & 54,0 & 28,0 & 26,0 & 21,0 & 30,0 & 31,0 & 33,0 \\
\hline Senegal & 49,0 & 44,0 & 37,0 & 25,0 & 14,0 & 11,0 & 24,0 & 30,0 & 26,0 \\
\hline Sierra Leona & 48,0 & 48,0 & 47,0 & 29,0 & 26,0 & 23,0 & 19,0 & 22,0 & 24,0 \\
\hline Sudáfrica & 38,0 & 29,0 & 23,0 & 14,0 & 8,0 & 18,0 & 24,0 & 21,0 & 5,0 \\
\hline $\begin{array}{l}\text { África al Sur del } \\
\text { Sahara }\end{array}$ & 48,0 & 45,0 & 40,0 & 20,0 & 16,0 & 18,0 & 28,0 & 29,0 & 22,0 \\
\hline $\begin{array}{l}\text { Países } \\
\text { industrializados }\end{array}$ & 17,0 & 13,0 & 11,0 & 10,0 & 9,0 & 9,0 & 7,0 & 4,0 & 2,0 \\
\hline Mundo & 32,0 & 26,0 & 21,0 & 12,0 & 10,0 & 9,0 & 20,0 & 16,0 & 12,0 \\
\hline
\end{tabular}

Fuente: Banco Mundial, Atlas del Banco Mundial e Informe sobre el Desarrollo Mundial (varios años); Informe sobre Desarrollo Humano, PNUD; UNICEF y UNFPA. Elaboración propia.

Si la tasa bruta de natalidad se aproxima al nivel de 50 por mil en 1970, a excepción de Sudáfrica, que ya se sitúa en el valor de 38 por mil, los índices de crecimiento natural, y los de incremento demográfico dependerán en gran medida de cuál es el grado de control de la mortalidad, cuya tasa se halla en promedio en 20 por mil, aunque la mediana se sitúa entre 25 y 30 por mil; y ésta parece que experimenta un cierto retroceso en el transcurso de la década de los 70 y también de los 80 , lo que explica que el saldo natural se sitúe en torno al $3 \%$ anual, porque la natalidad se mantiene alta en una gran parte de los países(Cuadro 4). 
Así, el crecimiento de la población del subcontinente se corresponde con el nivel del saldo natural, y varía de un país a otro por los diferentes niveles de mortalidad, que descienden en la década de los 80 . Ello se traduce en un incremento del saldo natural y de la tasas de crecimiento demográfico, hasta situarse alrededor del 3,5 anual. El de los años 80 es el mayor nivel de crecimiento poblacional de África al Sur del Sahara. En dos décadas parece que se produce el inicio de la consolidación de la transición epidemiológica, que supone el descenso de la tasas de mortalidad en unos 4 puntos, en tanto que la natalidad disminuye a un ritmo más lento, y, sobre todo, de una manera diferencial según países.

Pero en la década de los 90 las condiciones de vida empeoran en una gran parte de los países, por la ruptura del orden bipolar, y el consiguiente aumento de la pobreza, con la aparición de la epidemia de sida y la agudización de otras endemias, como la malaria, que conllevan un incremento anómalo e irregular de la mortalidad, cuestionando la evolución de la transición sanitaria. La tasa bruta de mortalidad es superior en 2004 en dos puntos a la de 1990, pero el aumento es grave en países en que la prevalencia del sida es muy alta, como Malawi, Mozambique, Botswana y Sudáfrica. En los dos últimos supone pasar de bajas tasas, por un gran control de las enfermedades infecciosas merced al grado de desarrollo social y económico logrado en décadas anteriores, a tasas propias de en torno a cerca de medio siglo antes. La consecuencia es la caída del crecimiento natural y de la población general. Si a ello se añade que la inestabilidad política (motivada también por la pobreza) genera cruentos conflictos civiles, como en Sierra Leona, Mozambique, Costa de Marfil, entre otros países, más las graves crisis de subsistencia por hambrunas, sobre todo en el Sahel, pero también en algunos países de África occidental, la situación en una gran parte de los países es de estancamiento e incluso de retroceso. De este modo cabe hablar de un cierto descenso del crecimiento natural y demográfico por el empeoramiento de las condiciones de vida al Sur del Sahara, hasta el punto que el índice de crecimiento se sitúa en el valor de $2,2 \%$ anual; y en gran medida obedece al proceso de incremento de la mortalidad, debida en particular al sida, lo que es muy grave en Malawi, Botswana y Sudáfrica. Ocurre también en casi todos los países del Sahel, por hambrunas, y en otros países afectados por guerras civiles, que han producido un aumento relevante de la mortalidad y sobre todo un gran desplazamiento hacia regiones vecinas de la población afectada, en un proceso de gran movimiento de refugiados. Todo ello incide en el descenso del incremento de la población, a lo que contribuye el proceso creciente, aunque limitado aún, del descenso de la natalidad y fecundidad en algunos países del subcontinente, por control voluntario de los nacimientos.

Paralelamente se ha producido un proceso de migración campo-ciudad, que conlleva una gran expansión de la población urbana, muy superior en la actualidad al incremento poblacional promedio de cada país. En el período 2000-2005 las tasas de crecimiento anual de la población siguen siendo muy elevadas en casi todos los países, en promedio en torno a 3\%, a excepción de tres grupos de países: el primero viene conformado por algunos países de África Occidental, como Guinea, Guinea Bissau, Senegal, Costa de Marfil, en que el flujo migratorio exterior, dirigido sobre todo a la Unión Europea, ha recortado el incremento de la población; el segundo, lo conforma algunos países de África Central, como la República Centroafricana y otros de África Oriental, como Malawi y Mozambique, cuya natalidad ha descendido algo, aunque se ha mantenido la mortalidad, y por último, el tercero viene dado por los países de África Austral, Botswana y Sudáfrica, cuya mortalidad ha aumentado de una forma sustantiva en la última década, recortando el crecimiento demográfico general, porque la natalidad además continúa con su proceso de reducción por la aplicación de una política demográfica tendente a la limitación voluntaria de los nacimientos. 


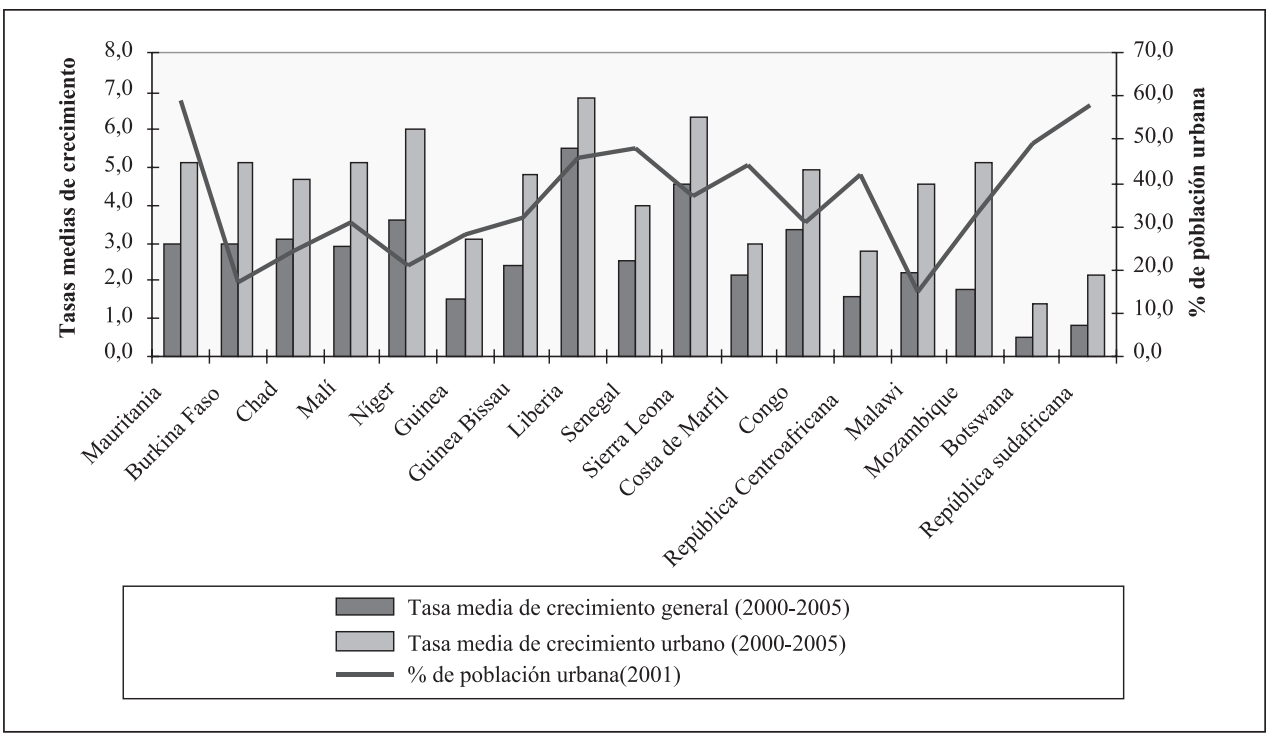

Figura 1. Tasas medias anuales de crecimiento de la población general y urbana Fuente: Informe sobre Desarrollo Humano, PNUD, y UNICEF. Elaboración propia.

Este crecimiento, muy elevado en casi todos países, se ha visto acompañado de una expansión sin parangón de la tasas de expansión de la población urbana, como una primera fase de la transición migratoria, campo-ciudad, paso previo a la segunda fase de la misma, esto es, a la emigración exterior (Figura 1). Es general a casi todos los países, y los índices se sitúan por encima de 5\% anual, a excepción en particular de los dos países ya mencionados de África Austral, en parte porque el proceso migratorio rural-urbano se produjo antes, debido al superior grado de desarrollo económico y al adelantamiento de la transición demográfica general ${ }^{13}$. Resultado de todo ello es que la proporción de población urbana es muy alta en estos últimos países, con más del 50\%, para descender en el resto, porque el proceso es más reciente. En general es de tipo medio, en torno a $40 \%$ en algunos países de África Occidental y Central, allí donde se ponen en marcha las pautas culturales relativas a la fecundidad de las áreas urbanas (aumento de la familia nuclear, mayor escolarización, por ejemplo), cuyos índices parece que comienzan a descender de un modo irreversible, aunque muy tardíamente, como veremos, y algo más bajo, en los países del Sahel, cuyo porcentaje de población urbana se sitúa en torno a $20 \%$, y donde la natalidad se ha mantenido casi inalterable.

\section{Una fecundidad cuasi natural: el escaso control y la aparición del comportamiento diferencial campo-ciudad}

Es evidente que la natalidad y fecundidad de África al sur del Sahara han evolucionado en su conjunto desde las altas cotas de los años 60-70, pues la tasa bruta de natalidad

13 Jean-Claude Chesnais introduce en 1986 la migración en el modelo de análisis de la transición demográfica (Bibliografía). 
se halla en esta época en torno a 48 por mil, muy próxima al nivel que podía alcanzar al principio de siglo $\mathrm{XX}^{14}$, esto es, se sitúa en el borde mismo del límite natural, como demuestra el Índice Sintético de Fecundidad de 6,7; probablemente éste aumentaría en un par de puntos decimales si se desagregase algunos países de África Austral, sobre todo, Sudáfrica ${ }^{15}$, que ya había iniciado el control voluntario de los nacimiento en el interior de la pareja (Cuadro 5).

\section{Cuadro 5}

EVOLUCIÓN DE LOS ÍNDICES SINTÉTICOS DE FECUNDIDAD

\begin{tabular}{|l|c|c|c|c|}
\hline & $\mathbf{1 9 7 0 - 7 5}$ & $\mathbf{1 9 9 1}$ & $\mathbf{2 0 0 3}$ & $\mathbf{2 0 0 5}$ \\
\hline Mauritania & 6,5 & 6,8 & 5,8 & 5,6 \\
\hline Burkina Faso & 7,8 & 6,5 & 6,7 & 6,5 \\
\hline Chad & 6,7 & 5,9 & 6,7 & 6,7 \\
\hline Malí & 7,6 & 7,0 & 7,0 & 6,8 \\
\hline Níger & 8,1 & 7,4 & 8,0 & 7,7 \\
\hline Guinea & 6,9 & 6,5 & 5,8 & 5,7 \\
\hline Guinea Bissau & 7,1 & 6,0 & 7,1 & 7,1 \\
\hline Congo & 6,3 & 6,6 & 6,3 & 4,8 \\
\hline Guinea Ecuatorial & 5,7 & 5,9 & 5,9 & 5,9 \\
\hline Senegal & 7,0 & 6,1 & 5,0 & 4,8 \\
\hline Sierra Leona & 6,5 & 6,5 & 6,5 & 6,5 \\
\hline Costa de Marfil & 7,4 & 6,6 & 4,7 & 4,8 \\
\hline República Centroafricana & 5,7 & 5,8 & 4,9 & 4,8 \\
\hline Malawi & 7,4 & 6,4 & 6,1 & 5,9 \\
\hline Mozambique & 6,6 & 6,5 & 5,6 & 5,3 \\
\hline Botswana & 6,8 & 4,8 & 3,7 & 3,1 \\
\hline República Sudafricana & 5,5 & 4,1 & 2,6 & 2,7 \\
\hline África Subsahariana & $\mathbf{6 , 7}$ & $\mathbf{6 , 1}$ & $\mathbf{5 , 3}$ & $\mathbf{5 , 1}$ \\
\hline África septentrional & $\mathbf{6 , 6}$ & $\mathbf{4 , 3}$ & $\mathbf{2 , 8}$ & $\mathbf{2 , 6}$ \\
\hline África & $\mathbf{6 , 7}$ & $\mathbf{4 , 9}$ & $\mathbf{3 , 3}$ & $\mathbf{3 , 6}$ \\
\hline
\end{tabular}

Fuente: Banco Mundial, Atlas del Banco Mundial e Informe sobre el Desarrollo Mundial (varios años); Informe sobre Desarrollo Humano, PNUD; UNICEF y UNFPA. Elaboración propia.

Parece razonable situar la datación del inicio de la baja de la natalidad y fecundidad en el transcurso de la década de los años 70 y 80, al menos en las áreas urbanas, y algo después, en los años 90 , en las rurales ${ }^{16}$, aunque aún hay países, como en particular los del Sahel, en que parece que los niveles se mantienen casi inalterables, con un escaso compor-

14 Vid P-J. Thumerelle, 1996 (Bibliografía).

15 Namibia se independiza en 1990.

16 Véase el interesante trabajo de V. Joseph et M. Garenne, 2001(Vid Bibliografía), aunque estos autores señalan que la transición en medio urbano comienza antes, en la década de los 70 por lo general, y en algunos países se retrasa hasta la década de los 80 e incluso 90. 

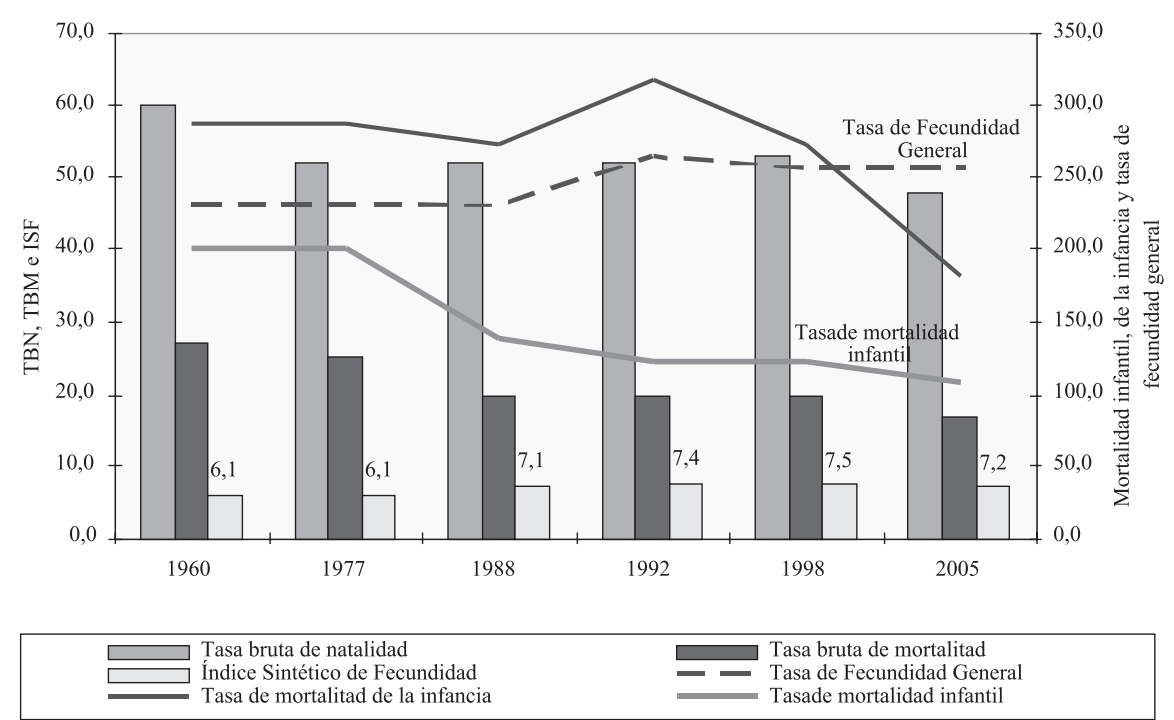

FiguRa 2. Evolución de variables sociodemográficas de Níger

Fuente: Institut National de la Statistique, Níger. Elaboración propia.

tamiento diferencial entre la ciudad y el campo, allí donde este proceso se ha iniciado. En 1990 la natalidad del subcontinente se sitúa en torno a 45,0, aunque con un rango de 28, entre el máximo de 57 de Níger y el mínimo de Sudáfrica de 29 por mil. Les corresponde una fecundidad de 7,4 y 4,1 respectivamente, de modo que en el área urbana de Níger se ha iniciado un cierto control de la fecundidad, aunque la información disponible no parece concluyente $^{17}$, en tanto que en Sudáfrica la diferencia ciudad-campo ya es muy relevante. El descenso en la década de los 80 es palpable en los países de África Austral, en Sudáfrica y Botswana (aquí algo más tardíamente), y parece manifestarse con cierta claridad en algunos países de África Occidental, como Costa de Marfil, Senegal, Ghana, Guinea y Guinea Bissau, pero en Sierra Leona el proceso en los 90 no se advierte, probablemente por la incidencia del conflicto bélico.

En muchos países el inicio de la inflexión parece retrasarse hasta la década de los 90, aunque comienza de una forma muy tímida, como ocurre en Burkina Faso (donde el porcentaje de población urbana es bajo), en el Sahel, Mauritania, en África Occidental, y en muchos de los situados en África Central, en la propia República Centroafricana, como lo confirman los tres indicadores esenciales de la natalidad y fecundidad. Algo más complejo parece ser el caso de Guinea Ecuatorial, por las deficiencias de la información estadística. Los índices específicos de fecundidad sí parecen indicar una cierta evolución,

17 V. Joseph et M. Garenne opinan que el inicio de la desviación entre la fecundidad urbana y la rural data de mediados de los 80 , pero es con probabilidad el alto porcentaje de población de los medios rurales, en torno al $80 \%$, lo que determina que el ISF sea aún muy alto en todo el país. Para estos autores hay un inicio reciente de descenso de la fecundidad rural, en torno a mediados de los 90 (Vid Bibliografía), aunque no parece traducirse aún de modo claro en el ISF del conjunto del país, por el gran peso aún hoy de la población del medio rural. 


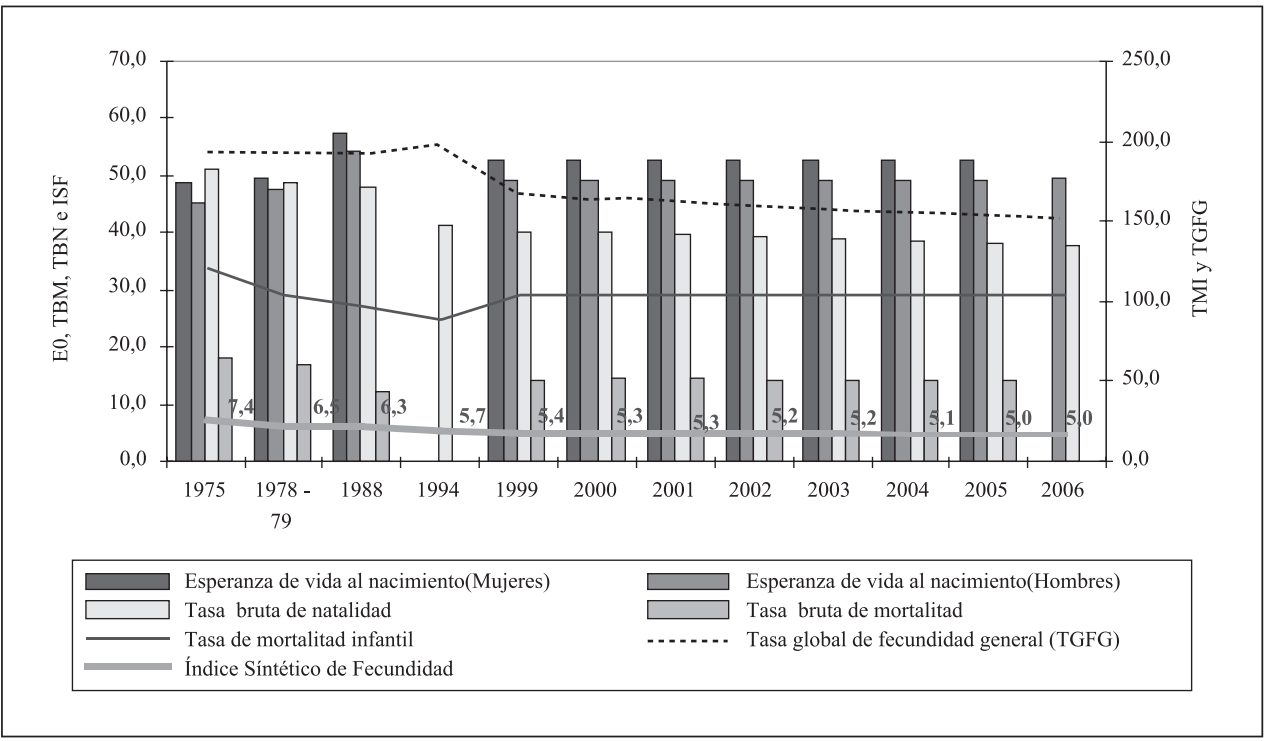

FIGURA 3. Evolución de variables sociodemográficas de Costa de Marfil

Fuente: Institut National de la Statistique (INS). Republique de Côte d'Ivoire. Elaboración propia.

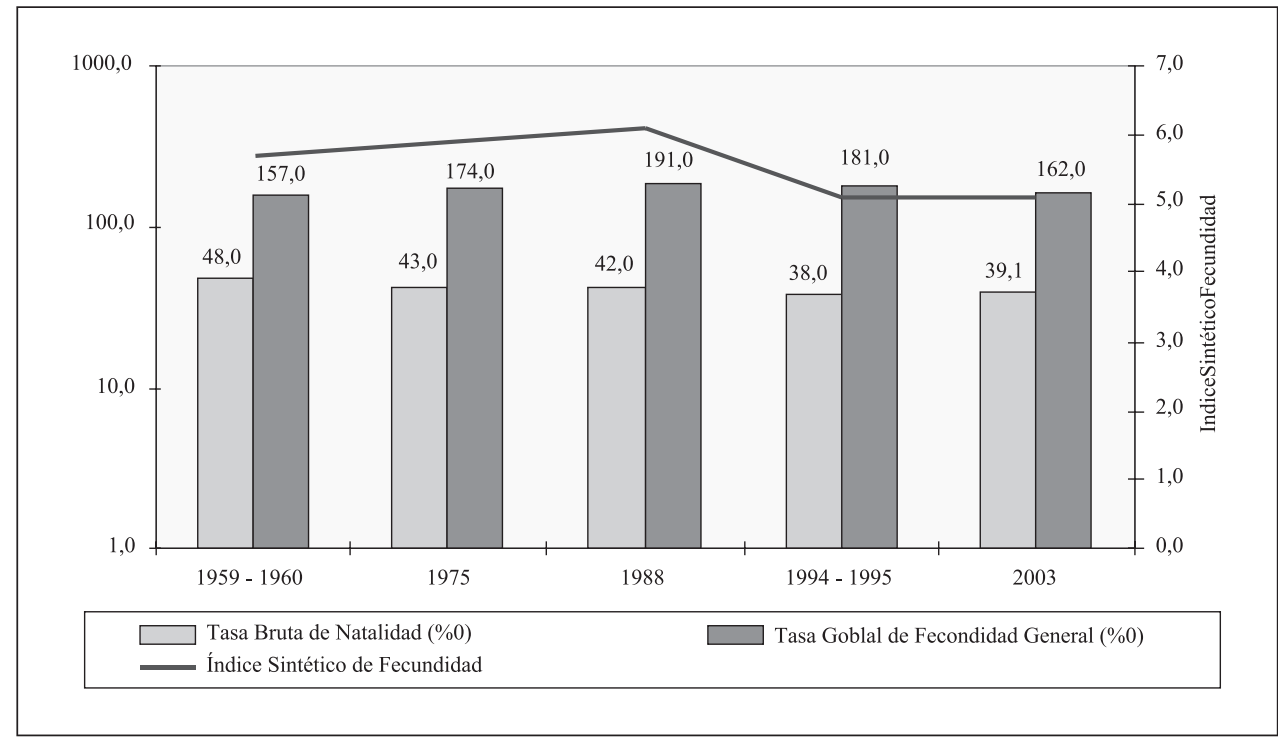

FIgURA 4. Evolución de indicadores de fecundidad de República Centroafricana

Fuente: Direction Genérale des Statistiques, des Études Économiques et Sociales, de República Centroafricana. Elaboración propia. 
aunque la tasa bruta de reproducción se mantiene en el nivel de 2,7 desde 1983 a 2001; pero es evidente que ya se ha producido una muy ligera inflexión, probablemente antes en las áreas urbanas, incluso antes de los años 70, razón por la que el ISF se sitúa ya por debajo de 6 . Como quiera que 2,1 de reemplazamiento generacional se corresponde con una contracepción de 75\% de las mujeres, al nivel de 2,7 le corresponde un porcentaje sensiblemente inferior, lo que contrasta con la gran proporción de población urbana, en torno a $48 \%$; fenómeno que se explica con toda probabilidad por las grandes diferencias de clases, en términos de desigualdad, incluso en el seno de las ciudades, por los efectos perversos del desarrollo petrolero que sólo ha beneficiado a la minoría más rica, cerca de los círculos del poder.

Cuadro 6

EVOLUCIÓN DEL NIVEL DE FECUNDIDAD DE BURKINA FASO

\begin{tabular}{|l|c|c|}
\hline & ISF & TFG (\% ( $^{\text {) }}$ \\
\hline 1960 & 6,1 & 199,0 \\
\hline 1975 & 6,7 & 212,0 \\
\hline 1985 & 7,2 & 223,0 \\
\hline 1991 & 7,3 & 223,0 \\
\hline 1993 & 6,9 & 233,0 \\
\hline 1996 & 6,8 & 213,0 \\
\hline $1998-99$ & 6,8 & 229,0 \\
\hline 2003 & 6,2 & 206,0 \\
\hline
\end{tabular}

Fuente: Institut National de Statistique et de la demographie (INSD), Burkina Faso. Elaboración propia

En ciertos países de África Oriental, como Malawi y Mozambique se confirma la inflexión leve de los años 90, aunque incluso se puede adelantar algo, hacia mediados de los $80^{18}$.

Cuadro 7

EVOLUCIÓN DE LOS ÍNDICES SINTÉTICOS DE FECUNDIDAD Y DE LAS TASAS BRUTAS DE REPRODUCCIÓN

\begin{tabular}{|c|c|c|c|c|c|c|}
\hline & \multicolumn{2}{|c|}{ Senegal } & \multicolumn{2}{c|}{ Costa de Marfil } & \multicolumn{2}{c|}{ Ghana } \\
\hline Circa & ISF & TBR & ISF & TBR & ISF & TBR \\
\hline 1980 & 7,2 & 3,5 & 7,2 & 3,5 & - & - \\
\hline 1988 & 6,6 & 3,2 & 6,8 & 3,3 & 6,4 & 3,1 \\
\hline 1994 & 6,0 & 2,9 & 5,7 & 2,8 & 5,5 & 2,7 \\
\hline 2004 & 4,9 & - & 4,9 & - & 4,2 & - \\
\hline
\end{tabular}

Fuente: Hasta 1994, T. Locoh y Y. Mardessi; 2004, UNICEF. Elaboración propia.

18 Para V. Joseph et M. Garenne, Malawi inicia la transición de la fecundidad en el medio rural hacia finales de la década de los 80, y no así en Mozambique en donde no se reconoce aún el inicio del descenso en las áreas rurales (Vid Bibliografía). 


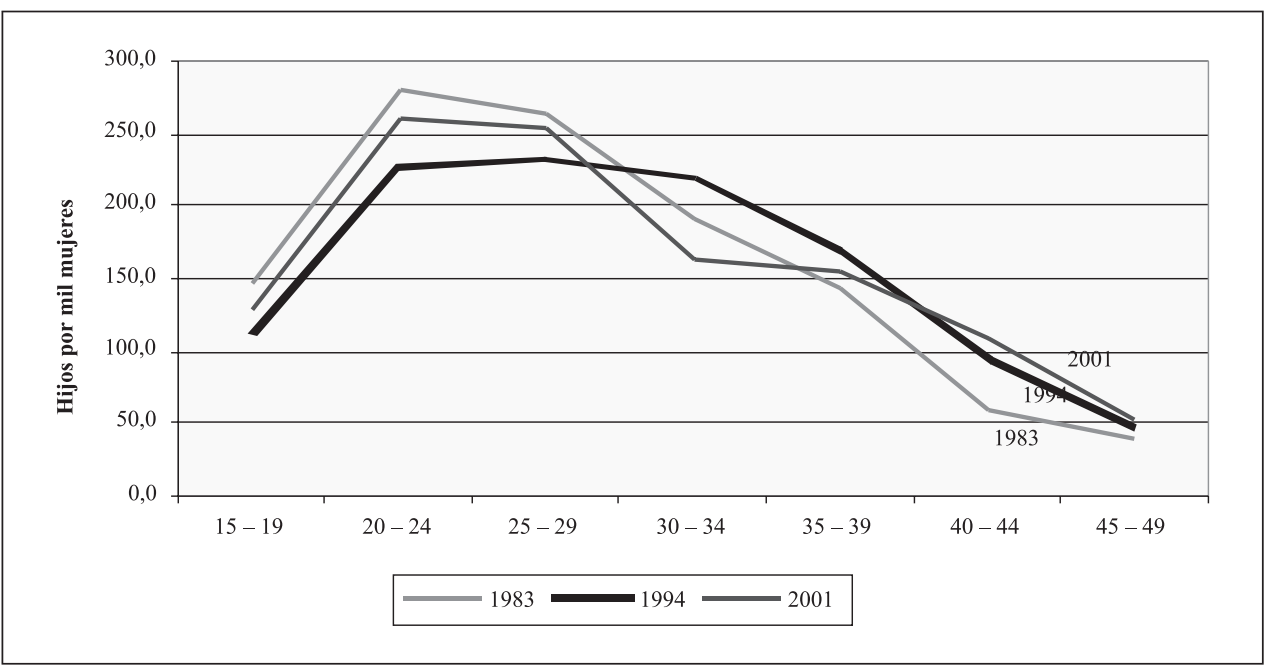

Figura 6. Evolución de los índices específicos de fecundidad de Guinea Ecuatorial Fuente: Dirección General de Estadística y Cuentas Nacionales, Guinea Ecuatorial. Elaboración propia.

Más que la datación del control de la fecundidad, interesa en este trabajo la situación actual de la misma en lo relativo a sus niveles, al grado de contracepción y en particular al comportamiento diferencial de las áreas urbanas y rurales de los países en estudio. En cualquier caso, la cronología propuesta por V. Joseph y M. Garenne (2001) parece muy acertada, al menos en líneas generales, en particular cuando señalan que el modelo general de transición de la fecundidad se caracteriza por el descenso primero en las áreas urbanas, y después, un decenio más tarde, en las áreas rurales. Así, la fecundidad en medio urbano comienza a reducirse en muchos países del subcontinente a mediados de la década de los 70 del pasado siglo, y pronto se manifiesta en los ISF. En algunos países como Kenia, Ghana, Togo, etc., el control en el medio urbano parece datar ya de los años 60, aunque para estos mismos autores la transición en las ciudades comienza para la mayoría de los países a mediados de los 70, y en algunos se retrasa hasta los años 80; así ocurre, por ejemplo, en la mayoría de los países del Sahel, en los que se inicia poco después el descenso en los medios rurales. Es claro el proceso en Níger y Burkina Faso, porque parece que en Malí y en Chad aún no se ha iniciado en las áreas rurales. En estos países la prevalencia de mujeres casadas de 15-19 años, en realidad adolescentes, se aproxima al 50\%, y similar proporción ha dado a luz antes de los 18 años, y ocurre igual en Guinea, Sierra Leona, República Centroafricana, Mozambique, y algo menos en Malawi (Cuadro 8). La prevalencia de mujeres casadas que usan método anticonceptivos modernos es bajísima en los primeros países citados, en realidad en casi todos los países en estudio, a excepción de Malawi, Mozambique y, evidentemente, Sudáfrica, con valores muy bajos en éste último de adolescentes casadas, aunque proporcionalmente la importancia relativa de mujeres de $<18$ que han dado a luz llega a una quinta parte, y la prevalencia de método anticonceptivos modernos es relativamente alta, en torno al $50 \%$, al menos en el contexto africano. 


\section{Cuadro 8}

ALGUNAS VARIABLES RELATIVAS A LA FECUNDIDAD EN 2005

\begin{tabular}{|l|c|c|c|c|c|}
\hline \multicolumn{1}{|c|}{ Países } & $\begin{array}{c}\text { \% de } \\
\text { casadas } \\
\text { alguna vez } \\
\text { de 15-19 } \\
\text { años }\end{array}$ & $\begin{array}{c}\text { \% de } \\
\text { mujeres } \\
\text { que han } \\
\text { dado a luz } \\
\text { antes de los } \\
\mathbf{1 8} \text { años }\end{array}$ & $\begin{array}{c}\text { \% de } \\
\text { partos de } \\
\text { mujeres de } \\
<\mathbf{2 0} \text { años } \\
\text { asistidos } \\
\text { por } \\
\text { personal } \\
\text { capacitado }\end{array}$ & $\begin{array}{c}\text { \% de mujeres casadas } \\
\text { que usan métodos } \\
\text { anticonceptivos } \\
\text { modernos }\end{array}$ \\
\hline Mauritania & & & & $\begin{array}{c}\mathbf{1 5 - 1 9} \text { años } \\
\text { de edad }\end{array}$ & $\begin{array}{c}\mathbf{2 0 - 2 4} \text { años } \\
\text { de edad }\end{array}$ \\
\hline Burkina Faso & 28,0 & 25,0 & 54,0 & 3,0 & 4,0 \\
\hline Chad & 32,0 & 27,0 & 55,0 & 4,0 & 9,0 \\
\hline Malí & 45,0 & 48,0 & 16,0 & 1,0 & 2,0 \\
\hline Níger & 49,0 & 45,0 & 44,0 & 4,0 & 7,0 \\
\hline Guinea & 62,0 & 47,0 & 17,0 & 2,0 & 5,0 \\
\hline Senegal & 46,0 & 47,0 & 45,0 & 5,0 & 6,0 \\
\hline Sierra Leona & 28,0 & 27,0 & 51,0 & 2,0 & 4,0 \\
\hline $\begin{array}{l}\text { República } \\
\text { Centroafricana }\end{array}$ & 47,0 & - & - & - & - \\
\hline Malawi & 42,0 & 38,0 & 51,0 & 2,0 & 3,0 \\
\hline Mozambique & 37,0 & 30,0 & 58,0 & 13,0 & 12,0 \\
\hline República Sudafricana & 4,0 & 20,0 & 88,0 & 48,0 & 53,0 \\
\hline
\end{tabular}

Fuente: UNFPA. El estado de la población mundial. Elaboración propia

Es probable que en la actualidad, a mediados de la década de 2000, casi todos los países africanos situados al sur del Sahara hayan encontrado el camino de la transición demográfica, antes en el medio urbano, y posteriormente, a partir de la década de 2010, en los espacios rurales.

Cronología aparte, interesa estudiar la situación actual pero la ausencia de fuentes estadísticas, sobre todo de encuestas demográficas recientes, impide un análisis en profundidad para todos los países analizados, por lo que se realizará para dos, Congo y Senegal, en los que se han llevado a cabo sendas encuestas y estudios para 2004 y 2005 respectivamente ${ }^{19}$. En el primero, en la Enquête démographique et de Santé de 2005 se puede observar de una forma palpable cómo el país avanza de una forma decidida en la senda de la transición en

19 Se trata de la Enquête démographique et de Santé du Congo (EDSC), 2005, en http://www.cnsee.org/ y de Situation économique et sociale du Senegal, Edition 2004 y Situation économique et social, 2004, Region de Dakar, Ministerio de 1'Economie et des Finances, en http://www.ansd.org/ 
Cuadro 9

ÍNDICES ESPECÍFICOS DE FECUNDIDAD DE LA REPÚBLICA DE CONGO EN 2005

\begin{tabular}{|l|c|c|c|c|c|c|}
\hline & $\begin{array}{c}\text { Brazza- } \\
\text { ville }\end{array}$ & $\begin{array}{c}\text { Pointe } \\
\text { Noire }\end{array}$ & $\begin{array}{c}\text { Otras } \\
\text { ciudades }\end{array}$ & $\begin{array}{c}\text { Conjunto } \\
\text { Urbano }\end{array}$ & Rural & Congo \\
\hline $15-19$ & 91,0 & 117,0 & 123,0 & 102,0 & 171,0 & 130,0 \\
\hline $20-24$ & 174,0 & 173,0 & 222,0 & 178,0 & 279,0 & 221,0 \\
\hline $25-29$ & 156,0 & 187,0 & 220,0 & 171,0 & 240,0 & 200,0 \\
\hline $30-34$ & 149,0 & 134,0 & 158,0 & 145,0 & 238,0 & 185,0 \\
\hline $35-39$ & 97,0 & 117,0 & 151,0 & 107,0 & 167,0 & 134,0 \\
\hline $40-44$ & 43,0 & 32,0 & 94,0 & 45,0 & 96,0 & 68,0 \\
\hline $45-49$ & 5,0 & 0,0 & 0,0 & 3,0 & 38,0 & 21,0 \\
\hline TBR & 1,7 & 1,9 & 2,4 & 1,8 & 3,0 & 2,3 \\
\hline ISF & 3,6 & 3,8 & 4,8 & 3,8 & 6,1 & 4,8 \\
\hline TGFG & 127,0 & 140,0 & 169,0 & 134,0 & 213,0 & 168,0 \\
\hline TBN & 32,9 & 36,4 & 39,8 & 34,6 & 46,2 & 40,1 \\
\hline
\end{tabular}

Fuente: Enquête démographique et de Santé du Congo (EDSC), 2005. Direction des Statiques Démographiques et Sociales. Elaboración propia

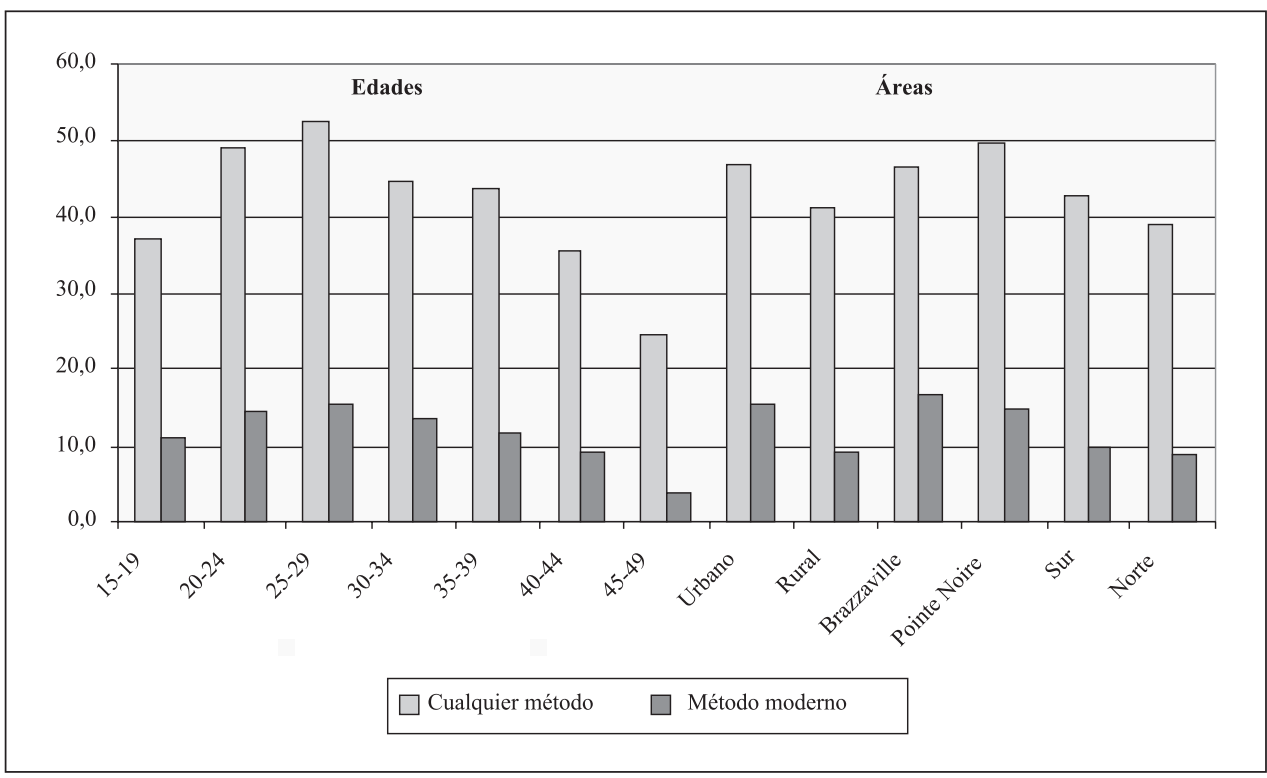

FIgURA 7. Uso de métodos contraceptivos por intervalos de edad de la mujer y áreas de residencia de la República de Congo en 2005

Fuente: Enquête démographique et de Santé du Congo (EDSC), 2005. Direction des Statiques Démographiques et Sociales. Elaboración propia. 
la fecundidad, porque el ISF ha descendido al valor de 4,8 para el conjunto del país, consolidándose en las áreas urbanas, pues Brazza-ville y Pointe Noire registran valores de 3,6 y 3,8 , respectivamente, lo que significa que cerca del $50 \%$ de las mujeres aplican alguna técnica anticonceptiva (Figura 7). En otras ciudades, de tamaño mediano e intermedio, el número de hijos por mujer asciende a 4,8, y finalmente en el medio rural el índice es de 6,1 , indicativo del inicio del descenso de la fecundidad, aunque aún en sus inicios, como indica el valor muy bajo de uso de medios anticonceptivos modernos.

\section{Cuadro 10}

DESIGUALDAD DE GÉNERO EN EDUCACIÓN EN ÁFRICA EN 2003

\begin{tabular}{|l|c|c|c|c|}
\hline & \multicolumn{2}{|c|}{ Alfabetización de adultos } & \multicolumn{2}{c|}{ Alfabetización de jóvenes } \\
\hline & $\begin{array}{c}\text { Tasa } \\
\text { femenina(\% } \\
\text { de 15 años y } \\
\text { más) }\end{array}$ & $\begin{array}{c}\text { Tasa } \\
\text { femenina } \\
\text { como \% de } \\
\text { la masculina }\end{array}$ & $\begin{array}{c}\text { Tasa } \\
\text { femenina(\% } \\
\text { de 15-24 } \\
\text { años) }\end{array}$ & $\begin{array}{c}\text { Tasa } \\
\text { femenina } \\
\text { como \% de } \\
\text { la masculina }\end{array}$ \\
\hline Mauritania & 43,4 & 73,0 & 55,5 & 82,0 \\
\hline Burkina Faso & 8,1 & 44,0 & 14,0 & 55,0 \\
\hline Chad & 12,7 & 31,0 & 23,1 & 42,0 \\
\hline Malí & 11,9 & 44,0 & 16,9 & 52,0 \\
\hline Níger & 9,4 & 48,0 & 14,2 & 54,0 \\
\hline Senegal & 29,2 & 57,0 & 41,0 & 70,0 \\
\hline Sierra Leona & 20,5 & 52,0 & 29,9 & 64,0 \\
\hline Costa de Marfil & 38,2 & 65,0 & 51,5 & 74,0 \\
\hline Ghana & 45,7 & 73,0 & - & - \\
\hline Congo(Brazzaville) & 77,1 & 87,0 & 97,3 & 99,0 \\
\hline Guinea Ecuatorial & 76,4 & 83,0 & 93,7 & 100,0 \\
\hline República Centroafricana & 33,5 & 52,0 & 46,8 & 67,0 \\
\hline Malawi & 54,0 & 72,0 & 70,7 & 86,0 \\
\hline Mozambique & 31,4 & 50,0 & 49,2 & 64,0 \\
\hline Botswana & 81,5 & 107,0 & 92,8 & 109,0 \\
\hline República Sudafricana & 80,9 & 96,0 & 94,3 & 101,0 \\
\hline Swazilandia & 78,1 & 97,0 & 89,4 & 103,0 \\
\hline África Subsahariana & $\mathbf{5 2 , 6}$ & $\mathbf{7 6 , 0}$ & $\mathbf{6 7 , 9}$ & $\mathbf{8 8 , 0}$ \\
\hline África & $\mathbf{4 3 , 1}$ & $\mathbf{6 6 , 5}$ & $\mathbf{5 5 , 0}$ & $\mathbf{7 6 , 4}$ \\
\hline Países en desarrollo & $\mathbf{6 9 , 6}$ & $\mathbf{8 4 , 0}$ & $\mathbf{8 1 , 2}$ & $\mathbf{9 2 , 0}$ \\
\hline Países menos adelantados & $\mathbf{4 4 , 6}$ & $\mathbf{7 0 , 0}$ & $\mathbf{5 6 , 8}$ & $\mathbf{8 1 , 0}$ \\
\hline & & & & \\
\hline
\end{tabular}

Fuente: Informe sobre Desarrollo Humano, PNUD. Elaboración propia. 
En Senegal, cuya transición en el medio urbano se había iniciado hacia los primeros años de la década de los 70, y en el rural entre 10 y 15 años después (V. Joseph y M. Garenne, 2001), el ISF de las mujeres de 15 a 49 años es para 2004 de 5,3 para el conjunto del país; no obstante, en el medio urbano desciende a 4,1, permaneciendo en las áreas rurales en torno a 6,4, por debajo del umbral de la fecundidad natural, en un nivel muy alto aún. En la región de Dakar, la prevalencia de mujeres, viviendo en unión, que usan métodos modernos de contracepción alcanza el valor de $18,6 \%$, pero para aquéllas que carecen de instrucción el porcentaje desciende a sólo $4,4 \%$, en tanto que para las que han cursado primaria es de 17,8 , y secundaria, de nada menos que $27,7 \%$. El escaso uso de métodos anticonceptivos modernos obedece a un nivel de instrucción que es realmente muy bajo en casi todos los países del subcontinente(a excepción de los del África Austral); hay además un factor que agrava el problema, por la gran desigualdad de género, pues la mujer, en cuya toma de decisión se halla la introducción de medidas contraceptivas y planificación familiar, presenta unas tasas de alfabetización por lo general más bajas, y aunque la situación mejora en algunos países, pues ya se detecta un aumento del nivel cultural en las mujeres jóvenes, las deficiencias son aun graves (Cuadro 10). De modo que hay una correlación evidente entre el medio de residencia y el nivel de fecundidad, así como también la hay entre los estudios realizados y el uso de métodos modernos de anticoncepción, y por consiguiente entre el uso de éstos y el nivel de fecundidad.

\section{El insuficiente descenso de la mortalidad: el predominio de la mortalidad infecciosa y parasitaria, la irrupción del sida y la crisis de la transición sanitaria}

Resulta muy complejo establecer el nivel de mortalidad del pasado, sobre todo en el momento en que comienza a producirse el proceso de descolonización de la mayoría de los actuales países de África al sur del Sahara, entre 1950 y 1970, aunque ciertamente unos pocos lograron su independencia antes, y otros en la década de los 70 e incluso 80 y $90^{20}$. J.-P. Thumerelle (1996) habla de un descenso de la mortalidad ya en plena fase colonial, debido a la introducción de métodos y técnicas para luchar contra las enfermedades infecciosas y parasitarias de la población autóctona, con el fin de lograr el aumento de la población, mediante reproducción biológica, de cara a la consecución de suficiente fuerza de trabajo para las explotaciones agrícolas tropicales y también para la minería. Pero la administración de las metrópolis nunca se preocupó por la dotación de infraestructuras sanitarias hospitalarias y de dispensarios públicos, por el equipamiento de medios y médico, y de personal sanitario y de prácticas de higiene pública, profilaxis y prevención de las morbilidades infantiles, como se demuestra en que las campañas de vacunación e inmunización fueron siempre una excepción ${ }^{21}$. De este modo, en ausencia de prevención generalizada alguna, la mortalidad, aunque pudo descender algo durante la colonización ${ }^{22}$, debió situarse en el nivel secular de 30-35 por mil, tal vez más próximo al último valor, porque las grandes fluctuaciones anuales eran la pauta común por la manifestación frecuente de graves crisis

20 Antes de 1950 sólo eran Estados independientes Egipto, Etiopía (antigua Abisinia), Liberia y Sudáfrica. Desde esta fecha hasta 1970 se descoloniza la gran mayoría de los actuales países de África, a excepción de las colonias lusas, que lo hacen unos años después. En 1975 se descoloniza en falso el Sahara español, y es un tema pendiente aún de resolución real y Namibia se independiza de Sudáfrica en 1990.

21 No se aplica campaña alguna de alfabetización y de aprendizaje de ciertas prácticas sanitarias tendentes a erradicar hábitos poco higiénicos, con lo que la responsabilidad de los nuevos líderes y dirigentes locales, tras la independencia, era desproporcionada ante el gran déficit dejado por la administración colonial.

22 J.-P. Thumerelle (1996) afirma que con toda probabilidad la vida media en Costa de Oro (actual Ghana) evolucionó de los 28 años a los 39 entre 1928 y 1950. 
de subsistencia por hambrunas (sequías, inundaciones, plagas de langosta, conflictos bélicos, con la pérdida de las cosechas) y de las epidemias, de cólera primero, fiebre amarilla, algunas de la infancia, como rubéola, tos ferina, más la diarreas, a lo que se debe añadir los efectos de las grandes endemias, como en particular el paludismo. Le corresponde una vida media que podía hallarse algo por debajo de los 30 años de edad. Es probable que el sistema colonial de control de ciertas enfermedades se derrumbase tras lo procesos de descolonización en casi todos los países, sobre todo en aquéllos que se independizaron de potencias muy centralizadas, como Francia, porque se desmanteló la escasa infraestructura y el equipamiento médico, al servicio sobre todo de la minoría blanca en el poder.

Así, resulta muy difícil admitir la tasa bruta de mortalidad de África Subsahariana de 22,2 por mil para 1965 (Cuadro 11), por deficiente, pues ésta, en sus valores medios seculares, no podía hallarse muy por debajo de 30 por mil, como parece indicar los valores de algunos de los países analizados: Níger, Sierra Leona, Mauritania y Mozambique (27, 33, 25 y 27 por mil respectivamente). Sudáfrica registra un valor de mortalidad de 14 por mil

\section{Cuadro 11}

EVOLUCIÓN DE LAS TASAS BRUTAS DE MORTALIDAD

\begin{tabular}{|l|c|c|c|c|c|}
\hline & $\mathbf{1 9 6 5}$ & $\mathbf{1 9 7 0}$ & $\mathbf{1 9 8 3}$ & $\mathbf{1 9 9 1}$ & $\mathbf{2 0 0 3}$ \\
\hline África Subsahariana & 22,2 & 21,2 & 17,5 & 16,5 & 18,6 \\
\hline África Septentrional & 21,0 & 18,2 & 14,3 & 11,0 & 8,0 \\
\hline África & 20,9 & 19,6 & 15,6 & 14,3 & 16,3 \\
\hline
\end{tabular}

Fuente: Banco Mundial: Atlas, Informe sobre el Desarrollo Mundial (varios años); Informe sobre Desarrollo Humano, PNUD; UNICEF. Elaboración propia

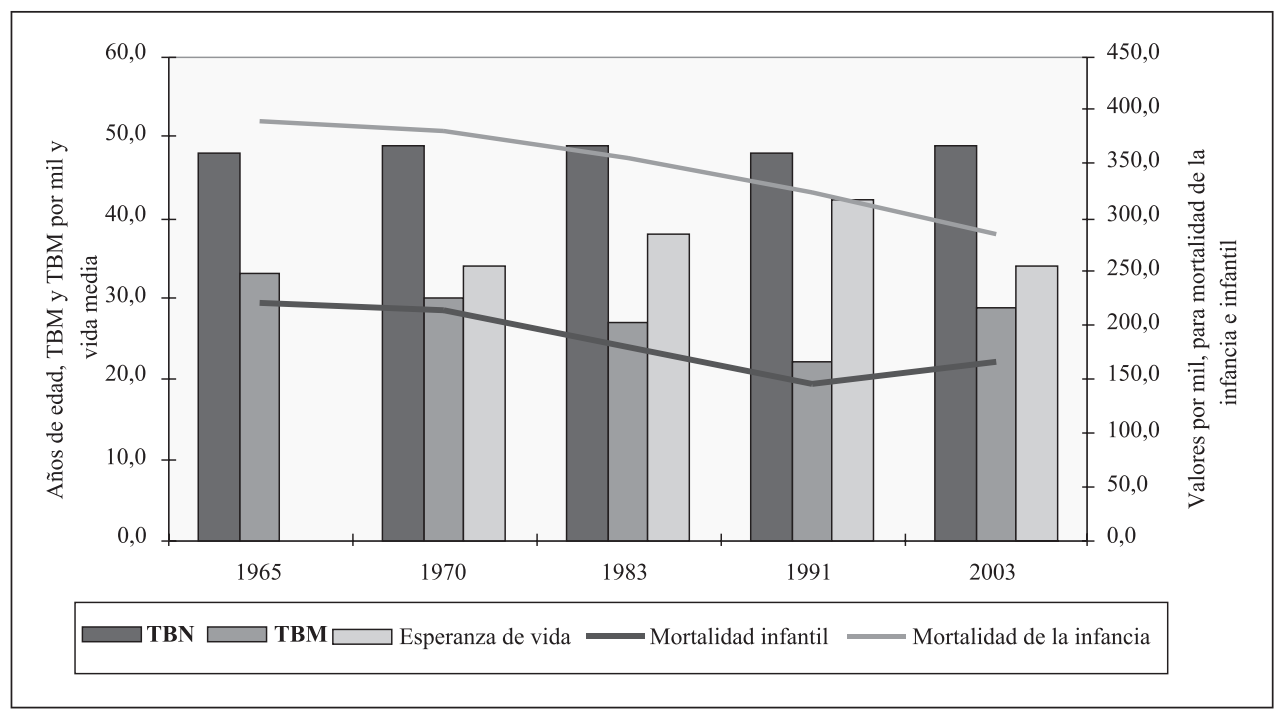

Figura 8. Evolución de los indicadores de Sierra Leona.

Fuente: Statistics Sierra Leone, Informe sobre Desarrollo Humano, PNUD y UNICEF. Elaboración propia. 
para 1970, porque el desarrollo humano se adelanta aquí al menos en tres o cuatro décadas. En esta época no hay un comportamiento diferencial entre África Septentrional y al Sur del Sahara, al menos de una forma sustantiva, aunque la brecha comienza a manifestarse muy pronto.

La novedad del modelo de mortalidad del subcontinente es el ritmo lento de retroceso con que se presenta con respecto al resto de las áreas del mundo no desarrollado, e incluso con los países del norte de África; y más novedoso es el proceso de crisis que se manifiesta a partir de la década de los 90, con la aparición del sida y la reactivación de ciertas endemias, que supone un nuevo incremento de sus valores para el conjunto del área y en particular para muchos países de alta prevalencia de aquellas morbilidades.

Parece evidente que hay dos etapas bien diferenciadas desde los años 60 hasta la actualidad, que se manifiesta de una forma palpable en una gran parte de los países:

A. De 1960-65 a 1990, en que la mortalidad desciende a un ritmo lento pero ininterrumpido: en 1983 es de 17,5 y en 1991 de 16,5 por mil. El retroceso es muy deficiente, comparado al que experimenta África del Norte, y sobre todo el conjunto de los países en vías de desarrollo. Así, en esta década la brecha se agranda con respecto al norte de África, pues la desviación es de nada menos que 5,5 puntos, pero resulta profunda con sólo compararla con la media del mundo, en torno a 10 por mil, y la de los países industrializados, 9 por mil(muy alta ésta porque en ella influye el envejecimiento demográfico). El ritmo de descenso resulta lento hasta el momento en casi todos los países estudiados, lo que se debe al estado en que queda las infraestructuras y equipamientos sanitarios tras la descolonización (THUMERELLE, 1996), deteriorándose en muchos por el proceso de agudización de la pobreza, los conflictos civiles, la inestabilidad política y la desarticulación de las estructuras de la administración de los Estados.

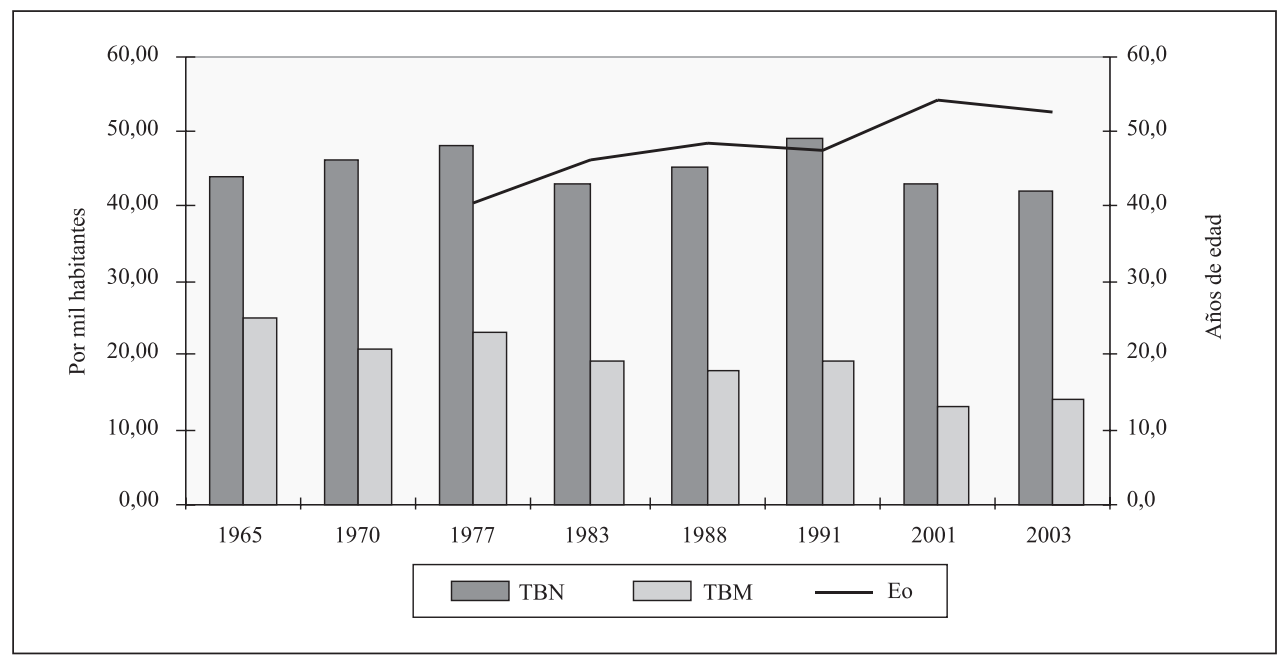

Figura 9. Evolución de las tasas anuales de natalidad y mortalidad y de la vida media de Mauritania

Fuente: Central Statistical Office, de Mauritania, Informe sobre Desarrollo Humano, PNUD y UNICEF. Elaboración propia. 
Evolución diferente es la de los países de África Austral: Botswana y Sudáfrica, 6 y 8 por mil respectivamente. La transición epidemiológica parece aquí asegurada. La evolución de la mortalidad infantil y de la infancia confirma estas tendencias, de manera que para el conjunto de África Subsahariana el retroceso es palpable, pues en la década de los 60 es de 152,0 por mil (la de la infancia alcanza el valor de 255) y unos treinta años después se sitúa en el de 111 por mil (y 181 para la infancia). Todavía en una gran parte de los países se alcanza valores muy elevados, en torno a 200 y 250 por mil para la infantil y la infancia respectivamente en 1960 , retrocediendo a 150 y 200 por mil en 1991 . Todo ello se traduce también en un incremento de la vida media, situándose por primera vez ligeramente por encima 50 años de edad. La brecha con África Septentrional se agranda también en todos los indicadores de la mortalidad, pues en ésta la vida media ya supera el umbral significativo de los 60 años de edad.

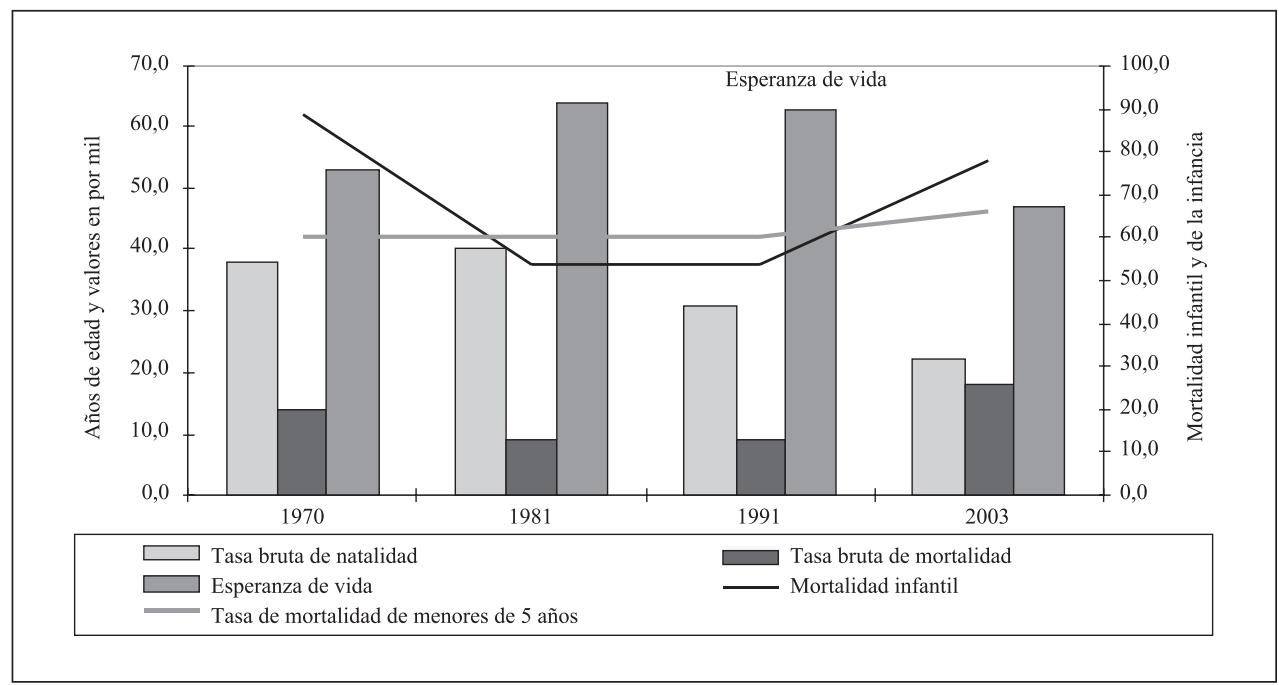

Figura 10. Evolución de los indicadores de Sudáfrica

Fuente: Central Statistical Service, South Africa, Informe sobre Desarrollo Humano, PNUD y UNICEF. Elaboración propia.

Cuadro 12

EVOLUCIÓN DE VARIABLES SOCIODEMOGRÁFICAS DE BOSTWANA

\begin{tabular}{|l|c|c|c|c|}
\hline & $\mathbf{1 9 7 1}$ & $\mathbf{1 9 8 1}$ & $\mathbf{1 9 9 1}$ & $\mathbf{2 0 0 1}$ \\
\hline Tasa General de fecundidad & 189,0 & 210,0 & 161,0 & 106,9 \\
\hline ISF & 6,5 & 6,6 & 4,2 & 3,3 \\
\hline Tasa de mortalidad infantil & 97,0 & 71,0 & 48,0 & 56,0 \\
\hline Mortalidad de la infancia & 152,0 & 105,0 & 63,0 & 74,0 \\
\hline
\end{tabular}

Fuente: Central Statistics Office, Bostwana. Elaboración propia 
El descenso es relevante, aunque muy insuficiente y de ritmo muy lento para la mayoría de los países, pero en Botswana y Sudáfrica, la mortalidad infantil y de la infancia alcanzan los valores de 48 y 51 por mil respectivamente, y lo más significativo tal vez es que disminuye considerablemente la mortalidad de la infancia, lo que indica la mejora indudable del sistema sanitario. La esperanza de vida al nacimiento se ha incrementado mucho, pues en estos países ya se supera los 60 años de vida media a principios de la década de los 90 . Las causas de mortalidad son, en esta fase, exógenas, infecciosas y parasitarias, en muchos casos cuasi endémicas, como la malaria, y en otros, las que afectan particularmente a la infancia, de carácter epidémico en muchas ocasiones: las diarreas, la tos ferina, el sarampión y la rubéola causan auténticos estragos, porque a las deficiencias en la higiene y de consumo de agua saneada se añade una muy baja prevalencia de vacunación y de inmunización de la población infantil e infanto-juvenil. La incidencia es grande en casi todos los países, pero se logran avances relevantes en África Austral, donde parece que se supera la transición epidemiológica.

B. La segunda fase se inicia en 1 os primeros años de la década de los 90 , y llega hasta hoy, con un final incierto, a medio o largo plazo. Significa un estancamiento relativo para el conjunto del subcontinente, y un retroceso evidente para algunos países. Situación que se manifiesta en un incremento de la tasa bruta de mortalidad en dos puntos con respecto a principios de la década de los 90, alcanzando el valor de 18,0 por mil en 2004. Ha descendido en algunos países, como Burkina Faso, Guinea, Guinea-Bissau, Malí, Mauritania, Níger, Senegal, aunque en muchos casos los ritmos son demasiados lentos.

En otros, por el contrario, el modelo de mortalidad ha experimentado un retroceso notable, hasta el punto de situarlo en la primera fase de la transición sanitaria, y en algunos aspectos en la fase cuasi pretransicional, aun obedeciendo a nuevas causas. La mortalidad infantil ha descendido algo, al igual que la de la infancia (de 111 a 104, de 255 a 175 por mil, respectivamente, en el curso de una decena de años), pero con una desaceleración que ha roto todas las previsiones y el cumplimiento de la irreversibilidad de este proceso. Las repercusiones en la vida media no se han hecho esperar mucho, porque en promedio para el conjunto del subcontinente se ha acortado en cerca de 6 años (de 51,3 a 45,7 años de edad en 2003), pero en muchos países los valores han descendido entre 10 y 15 años, como Botswana, Sudáfrica, Mozambique, Malawi, República Centroafricana, Congo, Costa de Marfil y Sierra Leona, por solo citar los países objeto de análisis (Cuadro 14). Es la gran prevalencia del Sida, que se ha vuelto una endemia muy grave en muchos países, coincidiendo a grandes rasgos con los que han registrado un mayor descenso de la esperanza de vida al nacimiento, con tasas de prevalencia en la población adulta de 15 a 49 años en 2003 que oscilan entre cerca del 40\% de Botswana y $7 \%$ de Costa de Marfil ${ }^{23}$.

23 En Sierra Leona la baja de la esperanza de vida se debe fundamentalmente a la guerra civil, que causó una gran mortandad. 
Cuadro 13

EVOLUCIÓN DE INDICADORES SOCIODEMOGRÁFICOS

\begin{tabular}{|c|c|c|c|c|c|c|}
\hline & \multicolumn{3}{|c|}{ Mortalidad infantil } & \multicolumn{3}{|c|}{$\begin{array}{l}\text { Mortalidad de la infancia } \\
\qquad(<\text { de } 5 \text { años) }\end{array}$} \\
\hline & 1960 & 1991-92 & 2003 & 1960 & 1991-92 & 2003 \\
\hline Mauritania & 191,0 & 119,0 & 96,7 & 321,0 & 206,0 & 183,0 \\
\hline Burkina Faso & 183,0 & 133,0 & 93,2 & 318,0 & 150,0 & 207,0 \\
\hline Chad & 195,0 & 124,0 & 115,3 & 325,0 & 209,0 & 200,0 \\
\hline Malí & 233,0 & 164,0 & 118,7 & 500,0 & 220,0 & 220,0 \\
\hline Níger & 191,0 & 126,0 & 125,7 & 320,0 & 320,0 & 262,0 \\
\hline Guinea & 203,0 & 136,0 & 101,7 & 337,0 & 230,0 & 160,0 \\
\hline Guinea Bissau & 336,0 & 148,0 & 120,0 & 336,0 & 239,0 & 204,0 \\
\hline Liberia & 192,0 & 134,0 & 147,4 & 288,0 & 217,0 & 235,0 \\
\hline Senegal & 174,0 & 81,0 & 60,7 & 303,0 & 145,0 & 137,0 \\
\hline Sierra Leona & 219,0 & 145,0 & 177,2 & 385,0 & 249,0 & 284,0 \\
\hline Costa de Marfil & 165,0 & 95,0 & 101,3 & 300,0 & 124,0 & 192,0 \\
\hline Congo & 143,0 & 69,0 & 84,0 & 220,0 & 110,0 & 108,0 \\
\hline Guinea Ecuatorial & 188,0 & 122,0 & 100,9 & 316,0 & - & 146,0 \\
\hline $\begin{array}{l}\text { República } \\
\text { Centroafricana }\end{array}$ & 174,0 & 106,0 & 100,4 & 294,0 & 179,0 & 180,0 \\
\hline Malawi & 206,0 & 144,0 & 115,4 & 365,0 & 226,0 & 178,0 \\
\hline Mozambique & 190,0 & 149,0 & 122,0 & 331,0 & 287,0 & 158,0 \\
\hline Botswana & 117,0 & 36,0 & 56,6 & 170,0 & 58,0 & 112,0 \\
\hline República Sudafricana & 89,0 & 54,0 & 47,9 & 126,0 & 70,0 & 66,0 \\
\hline África Septentrional & 126,8 & 76,1 & 65,5 & 188,2 & 119,0 & 69,2 \\
\hline África Subsahariana & 152,0 & 111,0 & 104,0 & 255,0 & 181,0 & 175,0 \\
\hline África & 164,5 & 98,2 & 83,2 & 274,2 & 165,3 & 138,1 \\
\hline Mundo & 127,0 & - & 54,0 & 198,0 & - & 80,0 \\
\hline
\end{tabular}

Fuente: Banco Mundial: Atlas, Informe sobre el Desarrollo Mundial (varios años); Informe sobre Desarrollo Humano, PNUD; UNICEF. Elaboración propia 


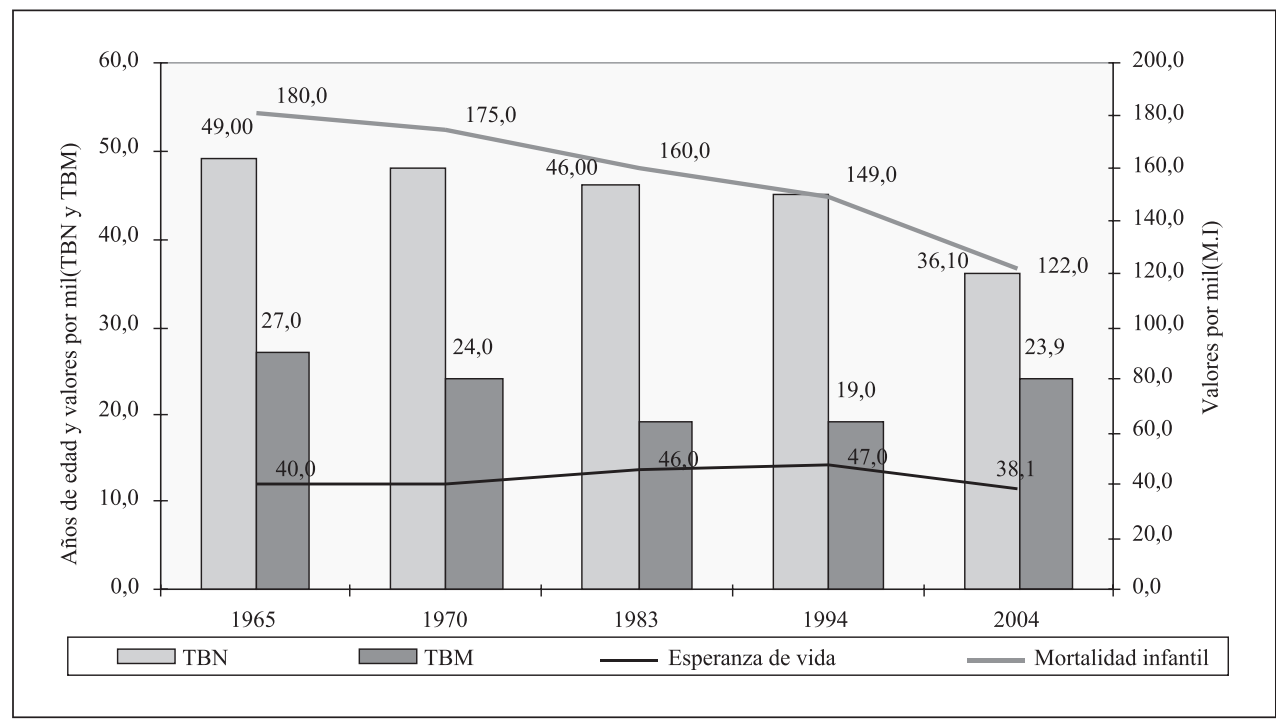

Figura 11. Evolución de los indicadores de Mozambique.

Fuente: National Institute of Statistics, de Mozambique, Informe sobre Desarrollo Humano, PNUD y UNICEF. Elaboración propia.

El problema es más grave aún porque la incidencia en la mujer resulta más elevada que en el hombre, con las repercusiones evidentes en el embarazo y en su descendencia. A ello se debe añadir una mortalidad materna muy elevada, pues la probabilidad de muerte por una causa relacionada con el embarazo es de una por cada 16, sin duda la más alta del mundo a escala de grandes regiones (una por cada 74 como media mundial). Las causas de mortalidad son las propias de la primera fase de la transición epidemiológica, esto es, las infecciosas y parasitarias, entre las que la malaria alcanza unas cotas muy elevadas, con las afecciones gastrointestinales en la infancia y ciertas epidemias infantiles que hoy carecen de importancia alguna en el mundo desarrollado. La pobreza, el bajo porcentaje del PIB que se dedica a salud, el escasísimo número de médicos (en muchos países la media se halla en torno a 2-4 por 100.000 por habitantes), las deficiencias en infraestructuras y equipamientos sanitarios, la baja escolarización, sobre todo de las niñas, los problemas de consumo de agua saneada, la baja inmunización y vacunación en la infancia, el mantenimiento de ciertas culturas tradicionales relativas a la higiene y que afectan a la profilaxis y prevención de muchas infecciones ${ }^{24}$, son las causas principales de este retraso en el régimen demográfico. Hay ya, no obstante, un comportamiento diferencial ciudad-campo, porque las condiciones generales mejoran habitualmente en los medios urbanos. Así, en Burkina Faso, la vida media es en 1996 de 56,3 en el medio urbano y de 52,2 años en el rural. En resumen, se puede establecer una tendencia en la cronología de la transición sanitaria (y también demográfica), como se propone en el cuadro 15.

24 Ciertas prácticas de la mujer en el parto, al aíre libre, y en muchas ocasiones en la propia vivienda, sin asistencia médica(los partos atendidos por personal sanitario especializado no llega en muchos países al 30\%), no son las más adecuada para la salud de la madre ni para la del recién nacido. 
Cuadro 14

EVOLUCIÓN DE LA VIDA MEDIA DE ALGUNOS PAÍSES

DE ÁFRICA SUBSAHARIANA

\begin{tabular}{|l|l|l|l|}
\hline & $\mathbf{1 9 8 3}$ & $\mathbf{1 9 9 2}$ & $\mathbf{2 0 0 3}$ \\
\hline Mauritania & 46,0 & 47,4 & 52,5 \\
\hline Burkina Faso & 44,0 & 47,9 & 45,7 \\
\hline Chad & 43,0 & 46,9 & 44,7 \\
\hline Malí & 45,0 & 45,4 & 48,6 \\
\hline Níger & 45,0 & 45,9 & 46,2 \\
\hline Guinea & 37,0 & 39,0 & 49,1 \\
\hline Guinea Bissau & - & 47,0 & 45,3 \\
\hline Senegal & 46,0 & 48,7 & 52,9 \\
\hline Sierra Leona & 38,0 & 42,4 & 34,2 \\
\hline Costa de Marfil & - & 51,6 & 41,0 \\
\hline Congo & $\mathbf{6 3 , 0}$ & 51,7 & 48,2 \\
\hline Guinea Ecuatorial & - & 47,3 & 49,1 \\
\hline República Centroafricana & 48,0 & 47,2 & 39,5 \\
\hline Malawi & 44,0 & 44,6 & 37,5 \\
\hline Mozambique & 46,0 & 46,5 & 38,1 \\
\hline Botswana & - & 60,3 & 54,7 \\
\hline República Sudafricana & 64,0 & 62,2 & 47,7 \\
\hline África Subsahariana & $\mathbf{4 9 , 2}$ & $\mathbf{5 1 , 3}$ & $\mathbf{4 5 , 7}$ \\
\hline África septentrional & $\mathbf{5 7 , 4}$ & $\mathbf{6 3 , 7}$ & $\mathbf{7 0 , 2}$ \\
\hline África & $\mathbf{5 0 , 0}$ & $\mathbf{5 2 , 6}$ & $\mathbf{4 9 , 1}$ \\
\hline
\end{tabular}

Fuente: Informe sobre Desarrollo Humano, PNUD; El estado de la población mundial, UNFPA y UNICEF. Elaboración propia.

\section{Consideraciones finales}

La pobreza de África Subsahariana en su conjunto viene dada por el bajo nivel de renta y de desarrollo humano general, que determina, en una interrelación dialéctica, su pauta de población, estancada y con retrocesos relevantes en algunas de sus variables. Así, las características esenciales de la relación dialéctica pobreza-población se manifiestan en un crecimiento demográfico fuerte y continuo, debido a la alta natalidad y fecundidad, con unos inicios tímidos y desiguales de transición; se halla muy correlacionada con el nivel de renta y con factores culturales y educativos. El nivel educativo resulta, en general, muy bajo, y deficiente es también la escolarización, con grandes diferencias de género, que redunda negativamente en el control de la fecundidad. Por otro lado, el inicio del control de la mortalidad general, hacia la transición epidemiológica, es lenta, frágil y tardía. Así, es muy alta la mortalidad infantil y de la infancia, y de desigual descenso, produciéndose un estancamiento notable, y retroceso en muchos países, en la última década. Resulta elevada la mortalidad exógena, infecciosa y parasitaria, y la esperanza de vida, baja, en torno a 
Cuadro 15

CRONOLOGÍA DE LOS INICIOS DE LA TRANSICIÓN DEMOGRÁFICA

\begin{tabular}{|l|c|c|}
\hline Países de inicio de: & Natalidad & Mortalidad \\
\hline $\begin{array}{l}\text { Transición temprana } \\
\text { antes de 1960) }\end{array}$ & Botswana, Sudáfrica & Botswana, Sudáfrica \\
\hline $\begin{array}{l}\text { Transición tardía } \\
\text { (entre los 60 y 80) }\end{array}$ & $\begin{array}{c}\text { Senegal, Costa de Marfil, } \\
\text { Guinea, Guinea Bissau, } \\
\text { Guinea Ecuatorial, Congo, } \\
\text { República Centroafricana }\end{array}$ & $\begin{array}{c}\text { Senegal, Costa de Marfil, } \\
\text { Guinea, Guinea Bissau, } \\
\text { Guinea Ecuatorial, Congo, } \\
\text { República Centroafricana }\end{array}$ \\
\hline $\begin{array}{l}\text { Transición muy tardía } \\
\text { (entre los 80 y 90) }\end{array}$ & $\begin{array}{c}\text { Mauritania, Burkina Faso, } \\
\text { Chad, Malí, Níger, Malawi, } \\
\text { Mozambique, Sierra Leona }\end{array}$ & $\begin{array}{c}\text { Mauritania, Burkina Faso, } \\
\text { Chad, Malí, Níger, Malawi, } \\
\text { Mozambique, }\end{array}$ \\
\hline $\begin{array}{l}\text { Estancamiento y } \\
\text { retroceso (desde } \\
1990)\end{array}$ & $\begin{array}{c}\text { Botswana, Sudáfrica, } \\
\text { - }\end{array}$ & $\begin{array}{c}\text { Malawi, Mozambique, Sierra } \\
\text { Leona }\end{array}$ \\
\hline
\end{tabular}

Elaboración propia.

los 45 años, retrocede en el conjunto de la región de una forma ligera, pero es muy grave en algunos países de alta prevalencia del Sida. No obstante, en esta gran área al Sur de Sahara hay disparidades territoriales manifiestas, pero las tendencias socioeconómicas, demográficas y espaciales son comunes y generales, con los debidos y relevantes matices que en muchas ocasiones se deben introducir en el análisis.

\section{Bibliografía}

ASHFORD. L. S. (2001): «Políticas de población: avances de los derechos de la mujer». Washington: Population Bulletin. Vol. 56, $\mathrm{N}^{\circ}$ 1.Une publication de Population reference bureau, marzo.

BANCO MUNDIAL. Informe sobre Desarrollo Mundial, Washington, años 1990, 1995 y 2002 у Atlas del Banco Mundial, años 1990, 1995 y 2004.

BANGHA, M. W. (2001): «Démographie et facteurs environnementaux. Les effets sur les programmes de maîtrise de la fecondité», en Régulations démographiques et environnement. CEPED, Paris, p. 103-111.

BAYA, B. et WILLEMS. M. (Éditeurs scientifiques) (2002): L'apport des approches renouvellées pour l'analyse du début de la transition démographique. Les Documents et Manuels du CEPED, Paris, $n^{\circ} 13$.

BOYER, P. et ALBAU, R. (1975): «Elements d'analyse de la transition démographique». Paris. Population, núm. 4-5, p 825-842.

CEPED (1994). La démogrphie de 30 Etats d'Afrique et de l'Océan Indien. Paris.

CHESNAIS, J-C. (1986): La transition démographique: étapes, formes, implications économiques, étude de séries temporelles (1720-1984) relatives à 67 pays. PUF-INED, Cahier $\mathrm{n}^{\circ} 113$, Paris.

CORVENIN, B. (1997): Le développement divergent des tiers-mondes après 1980: les rentes, freins aux transitions socio-démographiques et économiques. DEES/108. (En línea): http://www.cndp. fr/revuedees/pdf/108/06309411.pdf

COSIO-ZAVALA, M-E. (2002): «Baisse de la fecondité, développement humain et politiques de population», en L'apport des approches renouvellées pour l'analyse du début de la transition démographique. Les Documents et Manuels du CEPED, Paris, no 13, p. 59-67. 
COUSSY J. et VALLIN, J. (Dir.) (1996): Crise et population en Afrique. CEPED, Paris.

EL ESTADO DEL MUNDO. Anuario económico y geopolítico mundial. París: Éditions La Découverte y Ediciones Akal, años 1992, 2004, 2005 y 2006.

INTERMÓN OXFAM (Fundación para el Tercer Mundo) (2001.): África Subsahariana: un continente excluido. Perspectivas económicas para la región. (En línea): http://www.intermon.org/cms/ HTML/espanol/395/AfricaSubsahariana.pdf

JOSEPH, V. ET GARENNE, M. (2001): Datation de la baisse de la fecondité en Afrique subsaharienne, Le dossier du CEPED, $\mathrm{n}^{\circ}$ 66, Paris.

LERY, A. et VIMARD, P. (Coordenné par) (2001): Population et développement: les principaux enjeux cinq ans après la Conference du Caire. Les Documents et Manuels du CEPED, $\mathrm{n}^{\circ}$ 12, Paris.

LOCOH, T. et MAKDESSI, Y. (1996): Politiques de population et baisse de la fecondité en Afrique Sub-Saharienne. Le dossier du CEPED, $\mathrm{n}^{\circ}$ 44, Paris.

LOCOH, T. (1988): La fecondité en Afrique Noire: un progreso rapide des connaissances mais un avenir encore difficile a discernir. CEPED, Paris.

MUÑOZ CIDAD, C.: (1996): Estructura económica internacional, Editorial Civitas, Madrid.

NACIONES UNIDAS: WORLD POPULATION PROSPECTS (THE 1998 REVISION, THE 2004 REVISION). (En línea): http://esa.un.org/unpp

PNUD: Informe sobre Desarrollo Humano 2005. Ediciones Mundi-Prensa, Madrid.

POPULATION REFERENCE BUREAU: Cuadro de la población mundial, años 2002, 2004 y 2005. Washington. (En línea): http://www.prb.org/

ROLLET, C. (2004): La población en el mundo. Larousse, Paris.

THUMERELLE, P-J. (1996): Las poblaciones del mundo. Cátedra, Madrid.

UNICEF (1992): L'Afrique vers la reprise économique, (En línea): http://www.unicef.org/spanish/ publications/index_pubs_ac.html. y The Africa Malaria Report (En línea): http://www.unicef. org/publications/index_7936.html

UNICEF (2006): El estado Mundial de la Infancia. (En línea): http://www.unicef.org/publications/ index_7936.html

VALLIN, J. (1995): La demografía. Alianza Universidad, Madrid:

VAQUERO PUERTA, J. L. (1989): Salud pública. Pirámide, Madrid. 